\title{
Jan van den Hoecke (1611-1651), el pintor de Sibilas: éxito, inspiración y dispersión de una iconografía muy personal
}

\author{
Jan van den Hoecke (1611-1651), the painter of Sibyls: the success, \\ inspiration and dispersal of a very personal iconography
}

Jahel Sanzsalazar ${ }^{1}$

\begin{abstract}
Resumen: La autoría del pintor flamenco Jan van den Hoecke se reivindica en varias series de Sibilas, de variable número y calidad, atribuidas a otros pintores de la estela de Peter Paul Rubens en colecciones españolas y extranjeras, así como en el comercio del arte. Tanto las atribuciones como la identificación de los asuntos son objeto de una gran confusión que persiste y se esclarece en este artículo, en base a lo avanzado por Hans Vlieghe en 1990. Se sigue la pista de los diversos ejemplares hoy dispersos en la medida de lo posible, prestando especial atención a los lienzos del museo de Tessé de Le Mans, por ser el único ejemplo existente de una serie que se conserva unida. Jan van den Hoecke fue el creador de una iconografía original que se distancia de los precedentes formales. La comparación entre los diferentes ejemplares permite descifrar los textos en latín que acompañan cada representación, precisando sus fuentes literarias. A juzgar por la elevada cantidad de versiones localizadas, es tema que le proporcionó éxito y demanda que satisfizo con esfuerzo cambiante.
\end{abstract}

Palabras clave: Sibila, Jan van den Hoecke, Rubens, Jan Boeckhorst, Abraham Janssens, Filippo Barbieri, Musée Tessé

Abstract: Several series of Sibyls, of variable number and quality, that have been previously attributed to different painters within Peter Paul Rubens' circle, in foreign and Spanish collections, as well as in the art market, are here claimed to be by the hand of the Flemish master Jan van den Hoecke. The persistent confusion both in terms of attribution and identification of the subject matter is clarified in this paper, following on from Hans Vlieghe's 1990 evidence. Tracing the now dispersed series

1 ORCID iD: https://orcid.org/0000-0001-8564-9703

(c) 2019 Philostrato. Revista de Historia y Arte 
as far as possible, the present article pays special attention to the eleven canvasses at Tessé Museum, Le Mans, as they appear part of a unique ensemble that still remains undispersed. For these series Jan van den Hoecke created an original iconography, with no formal precedents. Comparison of the different versions allows for a deciphering of the Latin texts accompanying each depiction, and for an identification of their literal sources. Judging by the numerous versions, the series of Sibyls must have rewarded the artist with great success, a demand that he satisfied with a changeable effort

Key Words: Sibyl, Jan van den Hoecke, Rubens, Jan Boeckhorst, Abraham Janssens, Filippo Barbieri, Musée Tessé

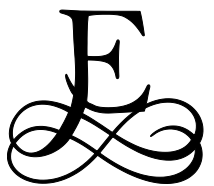

I tema de las Sibilas es uno de los más recurrentes en el coleccionismo de Amberes del siglo XVII ${ }^{2}$. Descritas en la mitología griega y romana, estas sacerdotisas poseedoras del don de la profecía se integraron en la tradición cristiana como pitonisas vaticinadoras de la venida del Mesías y las encontramos a menudo decorando las casas de nobles, burgueses, intelectuales, artistas, marchantes y religiosos de la época; que las poseían en series de número variable, en ocasiones asociadas con los doce emperadores romanos ${ }^{3}$. En la mayor parte de los casos se incluyen en los inventarios sin citar autor. Por ejemplo, el impresor Balthazar Moretus (1574-1641) tenía una serie de doce $^{4}$; también las había en las colecciones de los pintores Victor Wolfvoet $(1612-1652)^{5}$ y Jeremias Wildens $(1621-1653)^{6}$, del escultor Jacques Franchoys $(1646)^{7}$, en los inventarios de los marchantes Jan Liebrechts (1643) y Guillayume van Aelst $(1645)^{8}$, de militares como Francisco van den Brande (1653) o Herman van Omel (1655) ${ }^{9}$, y nobles como Guilham de Calvart, señor de Zeveren (1643), o Emerentiana Gallo de Salamanca (1654), hermana de Antonio, señor de Noirmont ${ }^{10}$.

\footnotetext{
2 Véase E. Duverger, Antwerpse kunstinventarissen uit de Zeventiende eeuw, XIV, (Brussel: Koninklijke Vlaamse Academie van België voor Wetenschappen en Kunsten, 2009), (Sibille).

${ }^{3}$ Así las encontramos, por ejemplo, en la colección de Suzanna Willemsens (1657). Duverger, Antwerpse Kunstinventarissen, VII, pp. 353, 394.

${ }^{4}$ Inventariadas al morir su viuda, Anna Goos, en 1691. Duverger, Antwerpse Kunstinventarissen, XII, p. 137.

5 Poseía una gran colección, con más de 600 pinturas registradas en su inventario post mortem (1652) y, entre ellas, una serie de "doce sibilas en tabla". Duverger, Antwerpse Kunstinventarissen, VI, p. 352, n०308.

6 Hijo del pintor Jan Wildens, fallecido en 1653, poseía varias series de sibilas: una de doce de mano de Jan Boeckhorst ("no 206-217. De Tweelf Sibillen van Joannes Binckhorst") y otra de cuatro sin citar autor ("n०. 454-457. Vier schilderijen de Vier Sebillen"). Duverger, Antwerpse Kunstinventarisse, VI, pp. $484,490$.

7 Según su inventario redactado en 1646. Duverger, Antwerpse Kunstinventarissen, V, p. 298.

8 Duverger, Antwerpse Kunstinventarissen, V, p. 108, 213.

9 Duverger, Antwerpse Kunstinventarissen, VI, p. 421; VII, p. 144.

10 Duverger, Antwerpse Kunstinventarissen, V, p. 110; VII, p. 40.
} 


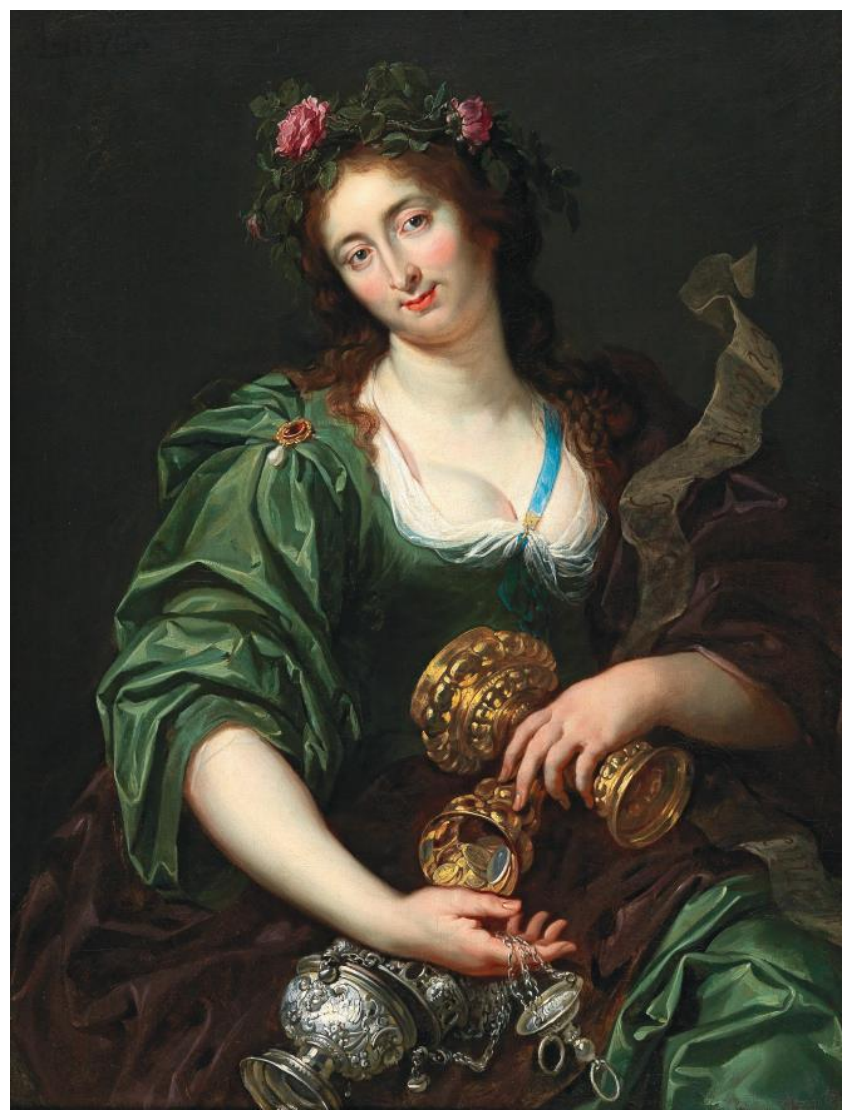

Fig. 1. Jan van den Hoecke. Sibila Líbica. Córdoba, colección particular. Foto del propietario@

Hoy en día la mayor parte de ellas están dispersas. Es quizá la razón por la que a menudo se confunden tanto su autoría como sus asuntos. Ya advertimos de la frecuente confusión que sufren las Sibilas de Jan van den Hoecke (Amberes, 1611-1651), atribuidas por error a otros pintores de la escuela de Rubens como Abraham Janssens (Amberes, 1567-1632), Jan Boeckhorst (Munster, 1604-Amberes, 1668), Gaspar de Crayer (Amberes, 1584-Gante, 1669), Theodoor van Thulden (Den Bosch, 1606-1669), Cornelis de Vos (Hulst, 1584-Amberes, 1651), Justus van Egmont (Leiden, 1602-Amberes, 1674) e incluso Peter Paul Rubens (Siegen, 1577-Amberes, 1640). A pesar del acertado artículo de 1990 del profesor Hans Vlieghe, quien restituye a Jan Van den Hoecke un buen número de sibilas que habían sido atribuidas por error a Jan Boeckhorst, y de la publicación en 2012 de la monografía de Boeckhorst, donde se rechazan como suyas ${ }^{11}$; la confusión

\footnotetext{
$11 \mathrm{H}$. Lahrkamp y G. Langemeyer, "Der "Lange Jan". Leben und Werk des Malers Johann Boeckhorst 1604-1668", Westfalen, 60, (1982), n 1, pp. 1-199; H. Vlieghe, "Nicht Jan Boeckhorst, sonder Jan van den Hoecke", Westfalen, 68, (1990), pp. 166-218; M. Galen, Johan Boeckhorst. Gemälde und Zeichnungen, Hamburg, 2012, pp. 361-363, cat. A4 (pinturas rechazadas); J. Sanzsalazar, "Jan van de Hoecke: quelques précisions et nouvelles propositions pour le catalogue de son oeuvre", Revue Belge d'archéologie et d'histoire de l'art/Belgisch tijdschrift voor oudheidkunde en kunstgeschiedenis, 82, (2013), pp. 45-78. De Jan Boeckhorst se inventaría una serie de doce sibilas en la colección de Jeremias Wildens, véase nota 5 .
} 


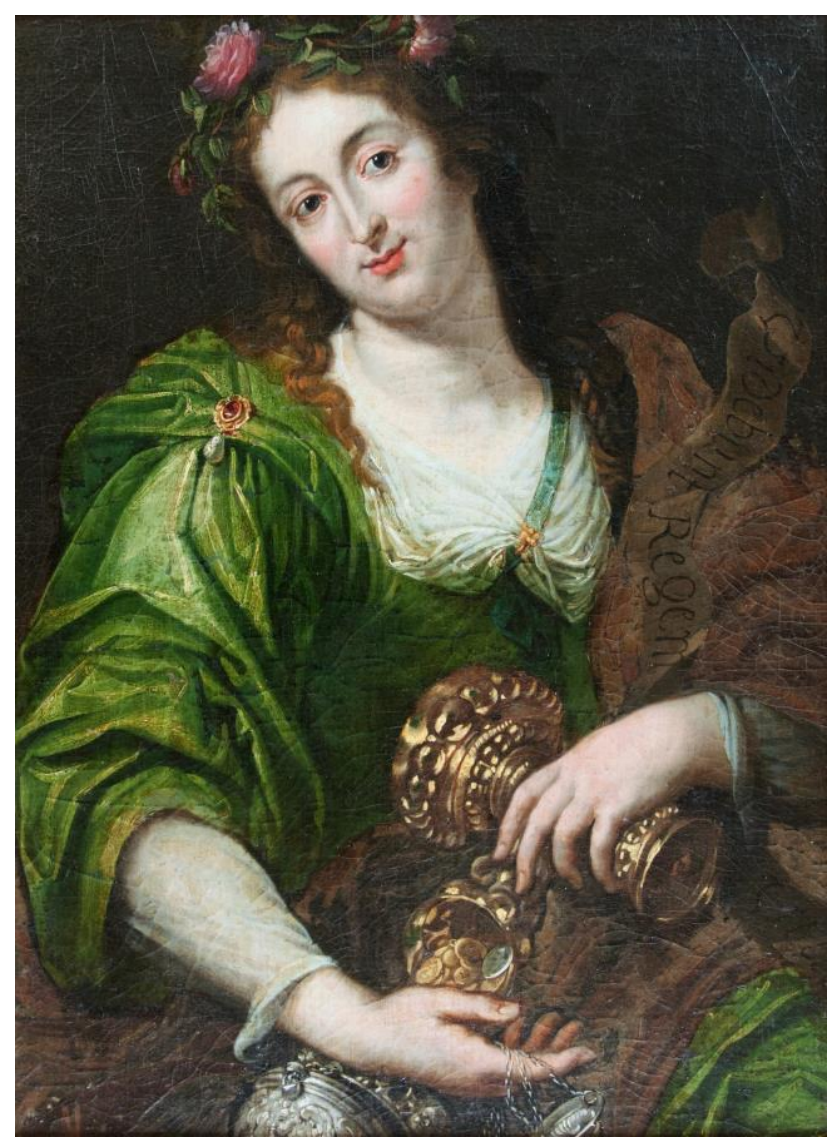

Fig. 1a. Jan van den Hoecke y taller. Sibila Líbica. Le Mans, Musée de Tessé@

no cesa, quizá por no tener el suficiente eco la bibliografía científica pertinente. También se confunden los asuntos, por desconocimiento de la iconografía de un tema, no obstante, arraigado tanto en la literatura clásica y medieval como en las Bellas Artes.

Recientemente Ilamó nuestra atención otro ejemplo, de notable calidad, procedente de una colección alemana, que ha sido adquirido por un coleccionista español ${ }^{12}$ (Fig. 1). Se tenía por una "Alegoría de la Fortuna", sin duda a causa de las monedas de oro que caen de los cálices y del rico incensario de plata repujada que sostiene entre las manos. No obstante, debió pasar inadvertida la inscripción "LIBYCA" que se lee en letras capitales y en negro en el margen superior izquierdo y que daba la pista para la correcta identificación del tema, pues se trata de la Sibila Líbica, cuya representación, al integrarse en la tradición cristiana, se asocia con objetos litúrgicos. Los cálices y el incensario de orfebrería han de interpretarse como una alusión al nacimiento de Cristo que la sibila vaticina, pues conti-

12 (Lienzo, 105,5 x 78 cm). Córdoba, colección privada (como Abraham Janssens, Alegoría de la Fortuna). 


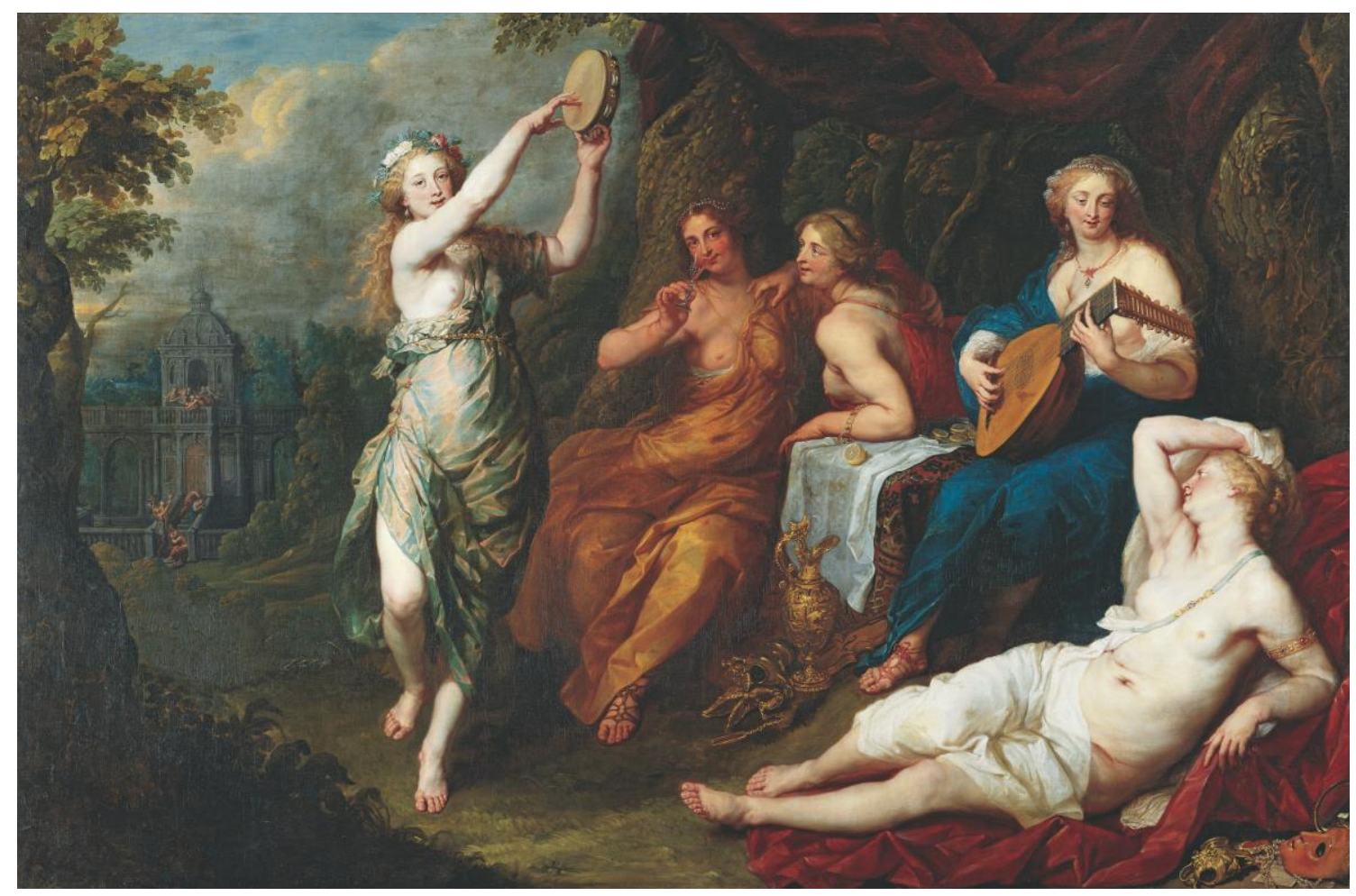

Fig. 2. Jan van den Hoecke. Las vírgenes necias. Vaduz, Fürstlich Liechtenstein Kunstsammlungen@

enen el oro, el incienso y la mirra con el que obsequiaron los reyes magos a Jesús recién nacido. De otra parte, en la filacteria que ondea sobre el hombro izquierdo de la profetisa se incluye un texto asociado a esta sibila en los textos: Videbunt regem viventium [Verán al rey de los vivientes] ${ }^{13}$, fragmento que proviene de un sermón contra los judíos del teólogo zaragozano e hijo de converso, Pedro de la Cavallería (1450), también presente en las muy divulgadas Discordantiae nonnullae inter sanctum Hieronymum et Augustinum de Filippo Barbieri (1481), donde se describe a la Sibila Líbica tal como la representa el pintor, con flores en la cabeza, anunciando el día en que se alumbrarán las tinieblas y cesará la sinagoga por la venida de Cristo concebido en el vientre de la Virgen ${ }^{14}$. Otro de los textos más antiguos en los que se inspiraron los artistas fue el Prophetie XII sibillarum de incarnatione Christi, manuscrito que conserva la universidad de Lieja, donde se describe con detalle la serie que poseyó el cardenal

\footnotetext{
13 Debemos al Dr. Guillermo Fatás las traducciones al castellano de los textos inscritos en las pinturas. Nuestro sincero agradecimiento por su amable ayuda y por sus valiosas observaciones.

14 "Sibila libica, ornata serta viridi et florum in capite, vestita palio honesto et non multum iuvenism si ait: Ecce veniet dies et illuminabit dominus condensa tenebrarum et solvet nexus synagoge, et desinent labia hominum et videbunt regem viventium; tenebit illum in gremio virgo domina gentium et regnabit in misericordia et uterus matris ius srit statura cunctorum". Pedro de la Cavalleria, Tractatus Zelus Christi contra Iudaeos, Sarracenos, \& infideles. Ab illust..., (Venetiis: Apud Baretium de Baretijs, 1592), p. 44.
} 
Giordano Orsini, proporcionando también inspiración para su representación en las bellas artes, en cuanto a la vestimenta, peinado, edad y atributos que debían portar ${ }^{15}$.

De nuevo se confundió la autoría con Abraham Janssens, quizá porque éste fue el autor de varias alegorías de los Cinco sentidos encarnados en la figura de una mujer con análoga disposición ${ }^{16}$. Se asemejan también a la serie de los Continentes de Jan Boeckhorst ${ }^{17}$, con quien también se confunden, al tener éste como precedente las Sibilas de Jan van den Hoecke $^{18}$. De Boeckhorst se conocen también dos sibilas, de estilo no obstante diferente a los que estudiamos aquí19. Esta Sibila Líbica es, por composición, modelos y estilo, típica de Jan van den Hoecke ${ }^{20}$. Su rostro es muy afín al de varias jóvenes en las Vírgenes necias de Jan van den Hoecke en la colección Liechtenstein de $V_{a d u z}{ }^{21}$ (Fig. 2), especialmente comparable a la que bebe una copa de vino, con idéntico diseño de los ojos y de la nariz, la boca con las comisuras de los labios levantadas esbozando la misma sonrisa y las mejillas sonrosadas de manera característica, una fisionomía que se repite en la que toca la pandereta, igualmente adornada la cabeza con una corona de flores. Al comparar ambas obras con cuidado es posible observar las múltiples correspondencias en la ejecución, percibir cómo coinciden los finos cabellos alrededor de la frente, la morfología de las manos de dedos gruesos y anchas muñecas, los brillos centelleantes de las telas, la forma triangular de los pliegues, y la atenta factura de las flores y de los objetos de orfebrería.

La existencia de un cierto número de repeticiones confirma la producción por parte del artista de varias series, lo que prueba su éxito. Como hemos apuntado, son numerosas las citas de Sibilas que figuran en los inventarios del coleccionismo de Amberes del siglo XVII sin mencionar autor. A nombre de Jan van den Hoecke se registran en la colección del pintor Erasmus Quellinus unas "Sittende Vrouwken van Van Hoeck" ["mujeres sentadas"], que quizá podrían corresponder con estas composiciones ${ }^{22}$. De la Sibila

\footnotetext{
15 M. Hélin, "Un texte inédit sur l'iconographie des sibylles", Revue belge de Philologie et d'Histoire, t. 15, fasc. 2, (1936), pp. 349-366.

16 Por ejemplo, la Alegoría de la Vista, del Oído y del Tacto del Rychnov Château, Rychnov nad Kněžnou, (inv. RK 277/1561; RK 279/1563; 276/150; 278/1562).

17 Sobre las series de los Continentes de Boeckhorst: Galen, Johan Boeckhorst, pp. 126-136.

18 Como apunta McGrath. E. McGrath, "Sibyls, Sheba and Jan Boeckhorst's 'Parts of the World'", en Florissant. Bijdragen tot de kunstgeschiedenis der Nederlanden (15de-17de eeuw). Liber amicorum Carl Van de Velde, (Brussel: VUB Press, 2005), p. 360.

19 Vlieghe, "Nicht Jan Boeckhorst...", p. 167; E. McGrath, "Sibyls, Sheba...", pp. 357, 359; Galen, Johan Boeckhorst, pp. 136-139, cats. 41, 42.

${ }^{20}$ A propósito del pintor: G. Heinz, "Studien über Jan van den Hoecke und die Malerei der Niederländer in Wien", Jahrbuch der Kunsthistorische Sammlungen in Wien, 63, (1967), pp. 109-164; Vlieghe, "Nicht Jan Boeckhorst...., pp. 166-183; J. Tátrai, "Jan van den Hoecke. Hercules at the Crossroads", en Arte Venustas. Studies on drawings in honour of Térez Gerszi, (Budapest, 2007), pp. 152-154; Sanzsalazar, "Jan van de Hoecke...", pp. 45-78.

21 (Lienzo, 225 x $341 \mathrm{~cm}$ ). Vaduz, Fürstlich Liechtenstein Kunstsammlungen. Vlieghe, "Nicht Jan Boeckhorst...", pp. 166-167.

22 Inventario levantado a la muerte de Quellinus en 1678. Duverger, Antwerpse kunstinventarissen, $\mathrm{X}$, p. 359.
} 
Cimeria hemos localizado nueve ejemplares, lo que implica que debieron existir al menos nueve series de variable número y calidad, cuya reconstrucción no es fácil dada su dispersión. La serie de la antigua colección Campbell, compuesta por ocho lienzos, parece ser de las mejores en calidad. No obstante, se desconoce su paradero desde 1951 y solo hay rastro de ella a través de antiguas fotografías. Las tres que estaban en posesión del marchante neoyorkino Weitzner en 1929, fueron adquiridas por la Bob Jones University en Greenville (EEUU) y vendidas en 1992. No hemos podido ver otras dos que señala Vlieghe en la colección Van den Schrieck de Lovaina ${ }^{23}$.

De muy próximas dimensiones es otro ejemplar, en fechas recientes en una galería alemana ${ }^{24}$, donde varía el color del fondo y de los mantos. La figura, más pequeña y con mayor espacio circundante, denota una concepción más lineal, una ejecución más somera en la configuración de los pliegues y menos rica en matices en las carnaciones y en los objetos metálicos de los que hace gala esta versión, de la que sin duda depende. El museo de Bellas Artes de Libourne conserva otra (inv. D.2004.1.70), que registra como anónima de la escuela flamenca, sobre la que ya advertimos en $2013^{25}$. El profesor Hans Vlieghe restituye a Jan van den Hoecke otras tres que se atribuyeron por error a Jan Boeckhorst: una que ilustra como Sibila sin nombre, pues la inscripción identificativa está ausente; y dos réplicas, en la antigua colección citada de B. Campbell Smith en Escocia, y en el museo de Bellas Artes de Le Mans ${ }^{26}$.

El caso de Le Mans es muy interesante, al ser el único ejemplo que conocemos donde once lienzos de un mismo conjunto se conservan juntos. Vale la pena reproducirlos aquí por primera vez, pues nos dan buena idea de las composiciones que se asocian; si bien, en cuanto a la ejecución, observamos una calidad más industrial, con presencia de repintes y mutilación de sus dimensiones ${ }^{27}$ (Figs. 1a, 3a-12a). La factura de los rostros es más cuidada que los atuendos y accesorios, tratados con mayor descuido. El hecho de que sean once no implica que la serie esté incompleta, pues la documentación relativa al coleccionismo demuestra que, si bien lo más común era que fueran doce, las series de Sibilas se

\footnotetext{
23 Vlieghe, "Nicht Jan Boeckhorst...", nota 5.

24 (Lienzo, $109 \times 78 \mathrm{~cm}$ ), con la inscripción "LIBICA" en blanco en la parte superior izquierda. Greven, Galen Galerie, 2015 (Jan van den Hoecke). Procede de Sarasota, Ford Art and Antiques; New Jersey, colección privada; Filadelfia, Freeman's auctions, (20.01.2015, lot 94; como escuela de Italia del Norte, siglo XVII y medidas $110,5 \quad x \quad 78,4 \quad \mathrm{~cm})$. Véase imagen en: http://auctions.freemansauction.com/full/347/919347.jpg (consultada: 8 de febrero de 2019)

25 Lleva la inscripción "3. LIBYCA", (Lienzo, 110,2 x 73,5 cm). Procede del legado Bertal, 1895. Vid. M. Stahl, Éloge du collectionneur Antoine-Victor Bertal (Créon, 1817-Nice, 1895), Cat. Exp. (Libourne: Chapelle du Carmel, Mai/Octobre 2006), pp. 78-79, no 21 (anónimo de la escuela flamenca, siglo XVII); Sanzsalazar, "Jan van den Hoecke...", p. 53, nota 41 (Jan van den Hoecke). Véase imagen en https://www.pop.culture.gouv.fr/notice/joconde/M0072003191 (consultada: 8 de febrero de 2019)

26 Vlieghe, "Nicht Jan Boeckhorst...", p. 167, nota 5, no 11, p. 170, fig. 11.

27 Varían en pocos centímetros las dimensiones de estos lienzos y, en la mayor parte de los casos, los temas están sin identificar. Nuestro agradecimiento a Flavien Dublanchet y a Françoise Froger-Jolivet, de los museos de Le Mans, por las imágenes y la información facilitadas respecto a esta serie. (Comunicación escrita, noviembre 2018).
} 
componían de un número variable $(3,5,6,7,11$ y 12$)$. Por ejemplo, una serie de once se registra en el inventario de Maria Anna Ghauwin (1693) ${ }^{28}$. En el museo francés estos lienzos están catalogados hoy como anónimos del círculo de Rubens, al desconocer la publicación de Hans Vlieghe que advertía de su autoría. De otra parte, al no contener inscripciones identificativas, no se han reconocido los asuntos. Es el caso de la repetición con la Sibila Líbica ${ }^{29}$ (Fig. 1a), identificada por error como "Sibila frigia". Es clara su dependencia, en composición y colorido, con el ejemplar en colección española (Fig. 1), pero inferior en calidad, como es notorio en la ejecución de los pliegues y en los pormenores de la orfebrería. Sin duda cortada en todos sus bordes, la repetición de Le Mans presenta la particularidad de cubrir los brazos de la sibila con una camisa, que bien podría responder a un repinte de pudor.

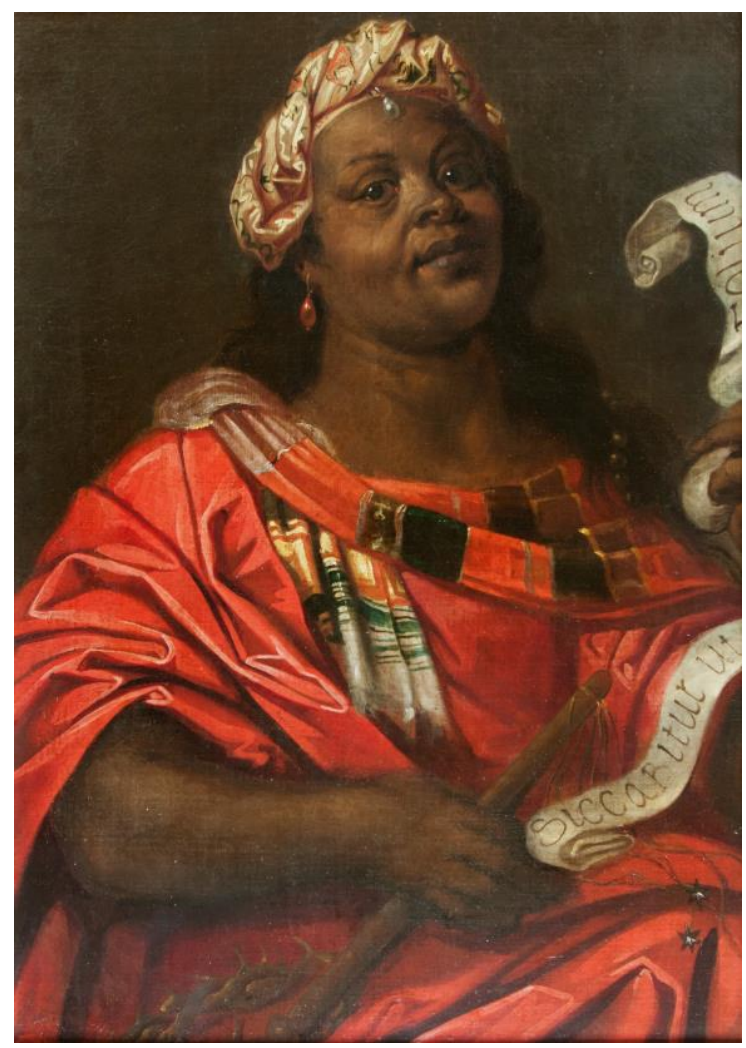

Fig. 3a. Jan van den Hoecke y taller. Sibila Agripina. Le Mans, Musée de Tessé@

\footnotetext{
28 Duverger, Antwerpse kunstinventarissen, XII, p. 275.

29 Sibila Líbica, descrita como "Sibila frigia", (Lienzo, 84,5 x $63 \mathrm{~cm}$ ). Le Mans, Musée de Tessé, (inv. no 10.641).
} 


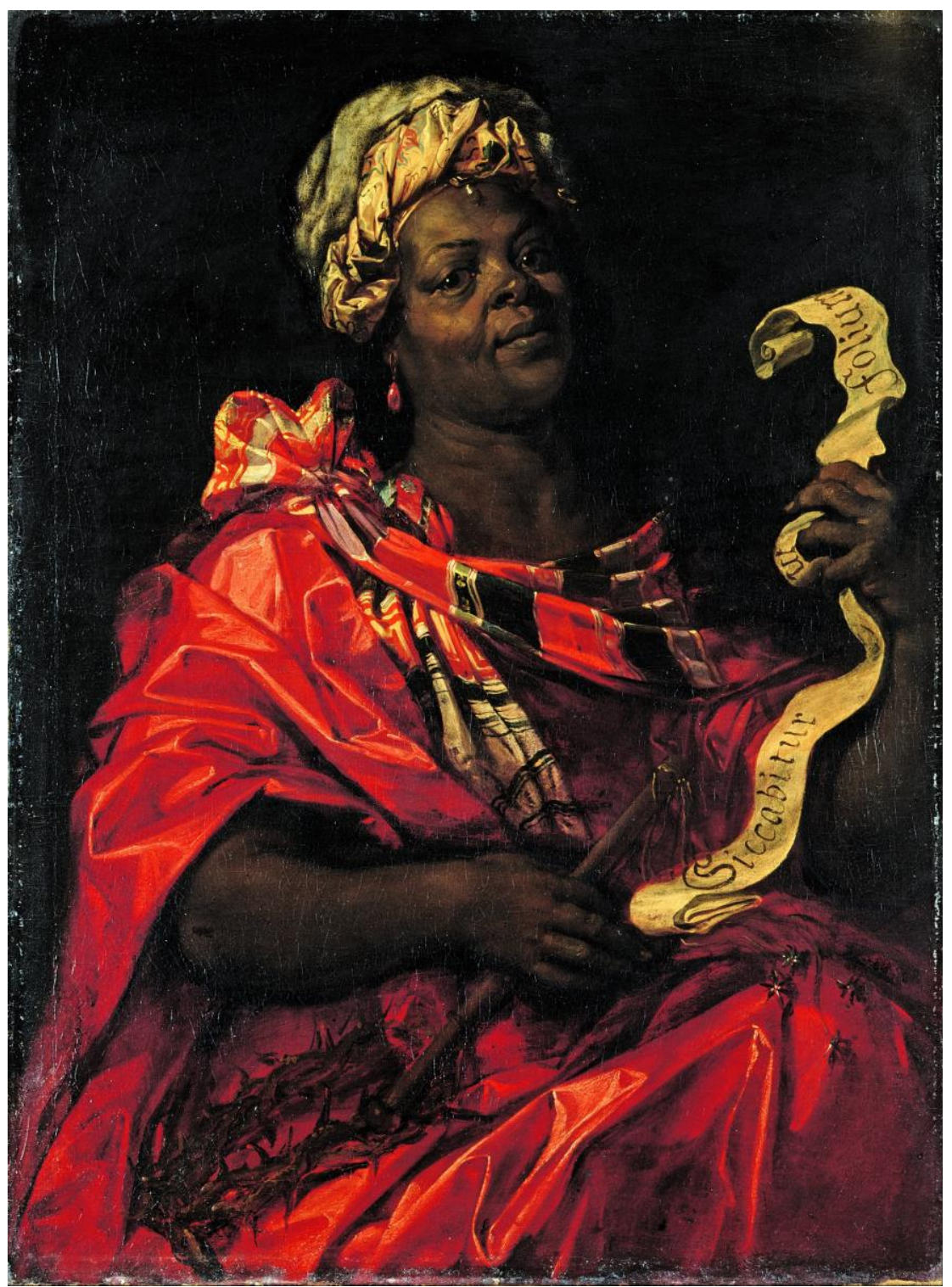

Fig. 3. Jan van den Hoecke. Sibila Agripina. Dusseldorf, Kunstpalast Gemäldesammlungen@

La Sibila Agripina, o Egipcia, lleva una filacteria donde se lee la inscripción: Siccabitur ut folium [Se secará como una hoja] ${ }^{30}$ (Fig. 3a), que procede de las Discordantiae de Barbieri. Es repetición del ejemplar que cita Vlieghe en la antigua colección Campbell ${ }^{31}$, y de otro conservado en el Museum Kunstpalast de Dusseldorf ${ }^{32}$ (Fig. 3). Cuando ésta última figuró en la muestra Black is beautiful en 2008, Elizabeth McGrath apuntó que Hoecke pudo inspirarse en los estudios de africanos de Rubens, concretamente en

30 (Lienzo, $87 \times 62,5 \mathrm{~cm}$ ), Le Mans, Musée de Tessé, (inv. no 10.638).

31 Vlieghe, "Nicht Jan Boeckhorst...", p. 166, nota 5, no 1; McGrath, "Sibyls, Sheba ...", p. 137, nota 9.

32 (Lienzo, 105,7 x 79,5 cm). Dusseldorf, Kunstpalast Gemäldesammlungen, (inv. no M125) (como Abraham Janssens). Vlieghe, "Nicht Jan Boeckhorst...", pp. 166-170, fig. 2, (como Jan van den Hoecke); McGrath, "Sibyls, Sheba...", pp. 357-370, fig. 8, (como Jan van den Hoecke); E. McGrath, in Black is beautiful: Rubens tot Dumas, (eds.) Elmer Kolfin y Esther Schreuder, (Zwolle: Waanders Publishers, 2008), cat. 22, (como Jan van den Hoecke). 
un hombre con turbante que retrató en Italia. Esta relación facilita una aproximación a la cronología de estas series de Sibilas, que corresponderían a los años 1630-1640, durante el periodo en que Hoecke colabora más estrechamente con Rubens. Hacia 1630 trabaja con él en las pinturas del Banqueting Hall de Londres y, hacia 1635, en las decoraciones para la Entrada triunfal del cardenal-infante en Amberes ${ }^{33}$. Es sabido que Hoecke se apropió hasta tal punto del estilo de Rubens que sus pinturas se confunden a menudo con las del maestro. Muy sonado fue el caso de la Masacre de los inocentes del museo de Ontario (expuesta hasta abril de 2019 en la Rubenshuis de Amberes), atribuida à Hoecke hasta su aparición en una galería londinense en 2001 , en que se restituyó à Rubens. La mano de Jan van den Hoecke empieza a distinguirse en las grandes composiciones de Rubens, como en la Subida al Calvario del museo de Bruselas ${ }^{34}$, al tiempo que empieza a deslindarse de la del maestro y su escuela. No obstante, sigue confundiéndose con la de otros pintores del círculo de Rubens como Erasmus Quellinus, Jan Boeckhorst y, como es el caso aquí, con Abraham Janssens ${ }^{35}$.

Otra sibila lleva en los brazos al Niño Jesús envuelto en una banderola con la inscripción: Invisibile verbum palpabitur [Se palpará el verbo invisible] parcialmente presente en el ejemplar de Le Mans $^{36}$ (Fig. 4a). Es texto que procede del Evangelio de San Juan (1:14), y profecía que Barbieri atribuye a la Sibila Agripina. No obstante, el pintor la pone en boca de la Sibila Tiburtina. En la ilustración de Barbieri la Tiburtina aparece junto a una aparición de la Virgen con el Niño en brazos, anunciando su nacimiento en Belén. Jan van den Hoecke ha traspuesto el motivo colocando al Niño en brazos de la propia sibila. Dos versiones de la Tiburtina localizamos en ventas españolas. Ya advertimos de la que figuró con indecisa atribución a Theodoor van Thulden en $1999^{37}$ (Fig. 4), que es de más fina calidad que otra ligeramente mayor aparecida en fechas más recientes como "escuela francesa del siglo XIX" y bajo el título de "Maternidad"38. Una copia de este prototipo de pobre calidad que localizamos en el comercio bruselense ${ }^{39}$ no

\footnotetext{
33 J.R. Martin, The decorations for the Pompa introtius Ferdinandi, Corpus Rubenianum Ludwig Burchard, (London-New York: Oxford University Press, 1972), pp. 142,146, 151; G. Martin, A. Balis (ed), Rubens. The Ceiling Decoration of the Banqueting Hall, Corpus Rubenianum Ludwig Burchard, (London-Turnhout: Brepols, 2005), pp. 73-78.

34 Natasha Peeters, en Joos van der Auwera (dir), Rubens, L'Atelier du génie, cat. Exp. (Bruxelles: Musées Royaux, 2007-2008), p. 205.

35 A propósito de la confusión con Jan Boeckhorst: Vlieghe, "Nicht Jan Boeckhorst...", pp.168-218; y de la confusión con Erasmus Quellinus, Sanzsalazar, "Jan van den Hoecke...", p. 49.

36 Identificada como "Sibila Samiana". (Lienzo, 78 x 61,5 cm). Le Mans, Musée de Tessé, (inv. no 10.642).

37 (Lienzo, $103 \times 74,5 \mathrm{~cm}$ ). La filacteria lleva la inscripción: "Invisibile verbum palpabitum". Madrid, Alcalá Subastas, (15/16-12-1999, lot. $n^{\circ} 29$, atribuido a Theodoor van Thulden). Sanzsalazar, "Jan van de Hoecke...", p. 53, nota 42 (Jan van den Hoecke).

38 (Lienzo, $107 \times 78 \mathrm{~cm}$ ), con la misma inscripción que la anterior. Madrid, Durán subastas, (18-022016 , lot. no 74, escuela francesa del siglo XIX, Maternidad).

39 (Lienzo, $99 \times 84 \mathrm{~cm}$ ). Lleva la inscripción en amarillo en la parte superior derecha: "TIPURTINA". Varía el texto de la filacteria: "REX. NASCETUR IN BETLEHEM". Bruselas, Brussels Art Auctions, (Juin 2016, lot. no 160, Ecole flamande XVIIe siècle).
} 


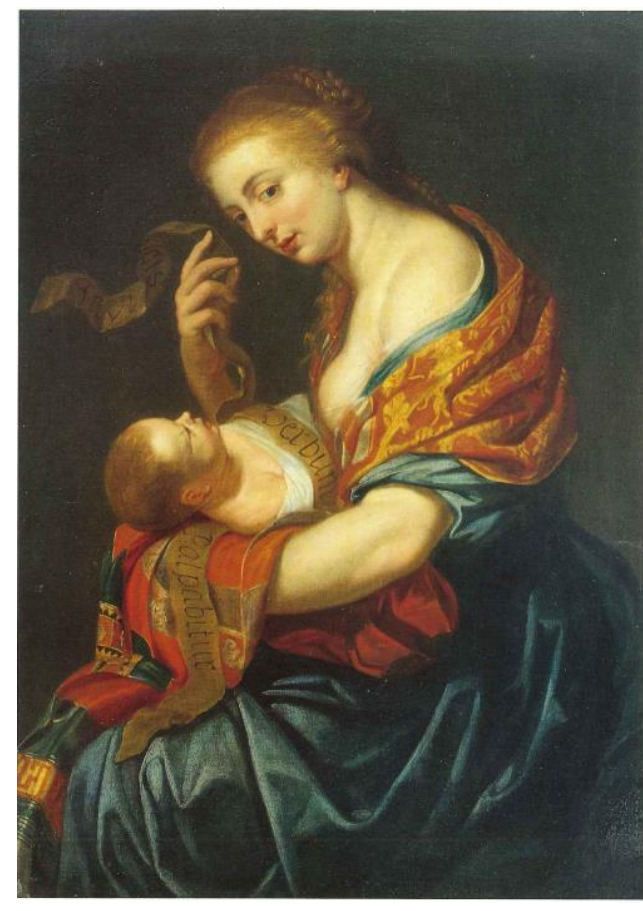

Fig. 4. Jan van den Hoecke. Sibila Tiburtina. Paradero actual desconocido

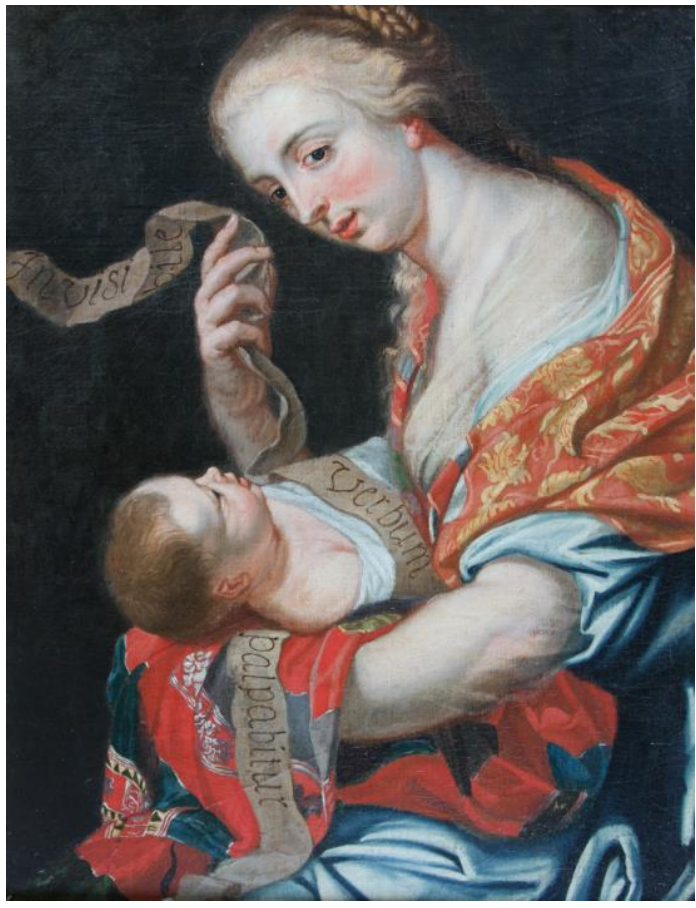

Fig. 4a. Jan van den Hoecke y taller. Sibila Tiburtina. Le Mans, Musée de Tessé(C)

deja de tener interés en cuanto al éxito de estas composiciones de Hoecke en pintores más mediocres.

La sibila que lleva un cuerno en la mano es la Sibila Délfica ${ }^{40}$ (Fig. 5a). La representación coincide con lo dicho en las Discordantiae de Barbieri, que la describe joven, vestida de negro, con el pelo recogido, llevando en la mano un cuerno o biberón, vaticinando que un profeta nacerá de una virgen ${ }^{41}$. Otros tres ejemplares cita Vlieghe en las antiguas colecciones de Campbell, General Hacquin de París (lienzo, 109 x 78 cm. 1935), y J. Wietzner de Nueva York (1929) ${ }^{42}$. Este último, como hemos apuntado, pasó a la Bob Jones University de Greenville (EEUU) antes de 1968 y fue vendido en $1992^{43}$. Un cuarto conocemos en colección privada española, con errónea

40 Identificada como "Sibila Cimeria", (Lienzo, 80 x 62,5 cm). Le Mans, Musée de Tessé, (inv. no 10.639).

41 "Sibilla Delphica vestita veste nigra et capillis circumligatis capiti, in manu cornu tenens et juvenis, quae ante Trojana belia vaticinata est, de qua Chrysippus; ait: Nascetur propheta absque matris coitu ex virgin ejus". Filippo Barbieri, en E. Mâle, L'Art réligieux de la fin du Moyen Age en France, [Paris, 1925], p. 259.

42 Vlieghe, "Nicht Jan Boeckhorst...", nota 5.

43 (Lienzo, 110,5 x 77,5 cm), con la inscripción: "6. Delphica". Nueva York, Julius J. Weitzner, n² 218, (como P. P. Rubens); Greenville, Bob Jones University, (inv. no P.63.312.11). Supplement to the catalogue the art collection, paintings acquired 1963-1968, (Greenville, S-Carolina: Bob Jones University, 1968]). Nueva York, Christie's (16-01-1992, lot. n 56, Circulo de Abraham Janssens). 


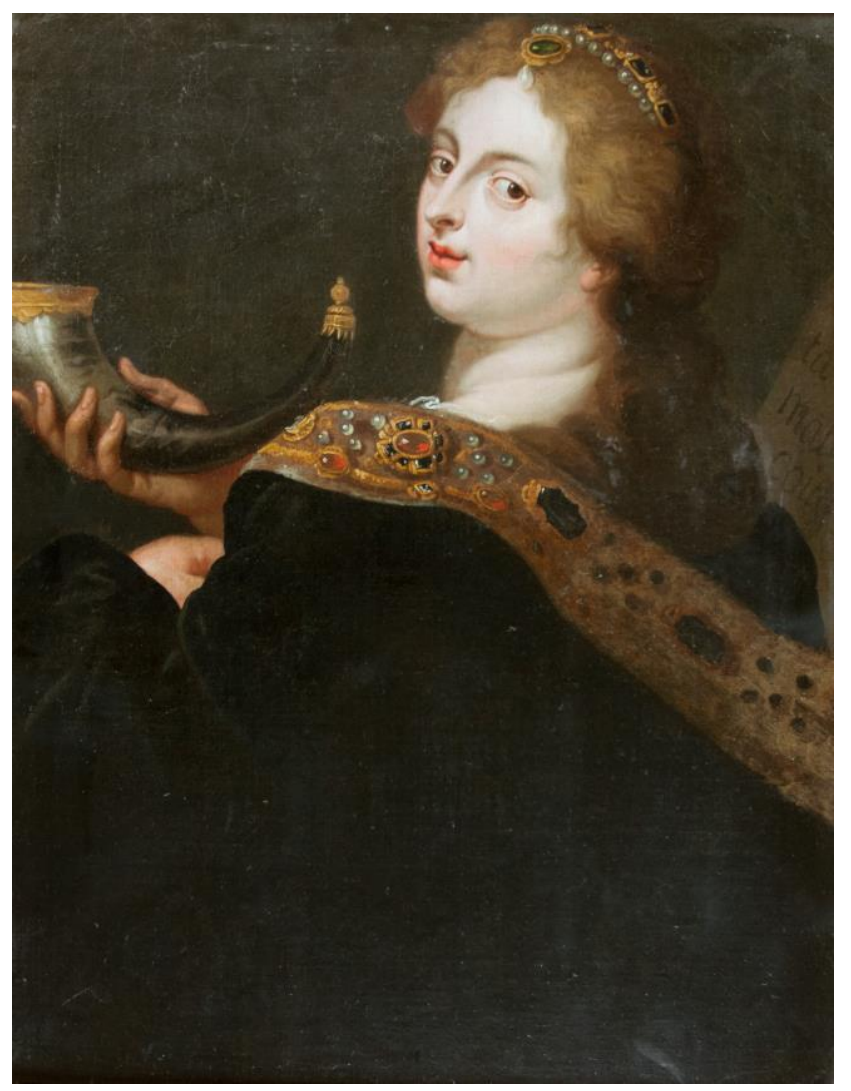

Fig. 5a. Jan van den Hoecke y taller. Sibila Délfica. Le Mans, Musée de Tessé(

atribución a Abraham Janssens ${ }^{44}$ (Fig. 5); y otro en el mercado artístico alemán con atribución imprecisa al círculo de Rubens ${ }^{45}$. Es posible en estos últimos leer el texto del libro, tomado de Barbieri, que aparece cortado en el ejemplar del museo de Le Mans: Nascetur propheta absque matris coitu ex virgine ejus [Nacerá un profeta de una virgen, sin coito de su madre].

La sibila que lleva una red en la mano y pescados en el regazo es la Eritrea $^{46}$ (Fig. 6a). Conocemos, en colección privada madrileña, un bello ejemplar que se tuvo por obra del círculo de Gaspar de $\operatorname{Crayer}^{47}$ (Fig. 6). Ostenta su nombre en una banderola arriba a la izquierda acompañada del número 8. Detrás, un libro abierto con la inscripción de su profecía. La asociación con el pescado se explica por la etimología de Ichthus [en griego: pez], que es el nombre místico del Salvador, formado al unir las primeras letras de Iesus, Khristos, Theu huios, Soter [Jesucristo, hijo de

44 (Lienzo, $99 \times 66 \mathrm{~cm}$ ). Córdoba, colección privada (atribuido a Abraham Janssens). Este ejemplar presenta alteraciones de los barnices y ganaría prestancia con una adecuada limpieza y restauración.

45 (Lienzo, $105 \times 78 \mathrm{~cm}$ ), con la inscripción en azul grisáceo, en la parte superior izquierda: "DELPHICA / 6". Colonia, Lempertz auktion, no 1132, (18-05-2019, lot. no 1238, círculo de Peter Paul Rubens). Véase imagen en https://www.lempertz.com/de/kataloge/lot/1132-1/1238-peter-paul-rubens-umkreis.html (consultada 3 de mayo de 2019)

46 Descrita como "Sibila con red y pescados", (Lienzo, 84 x 62,5 cm). Le Mans, Musée de Tessé, (inv. no 10.640).

47 (Lienzo, $106 \times 78 \mathrm{~cm}$ ). Madrid, colección particular. 


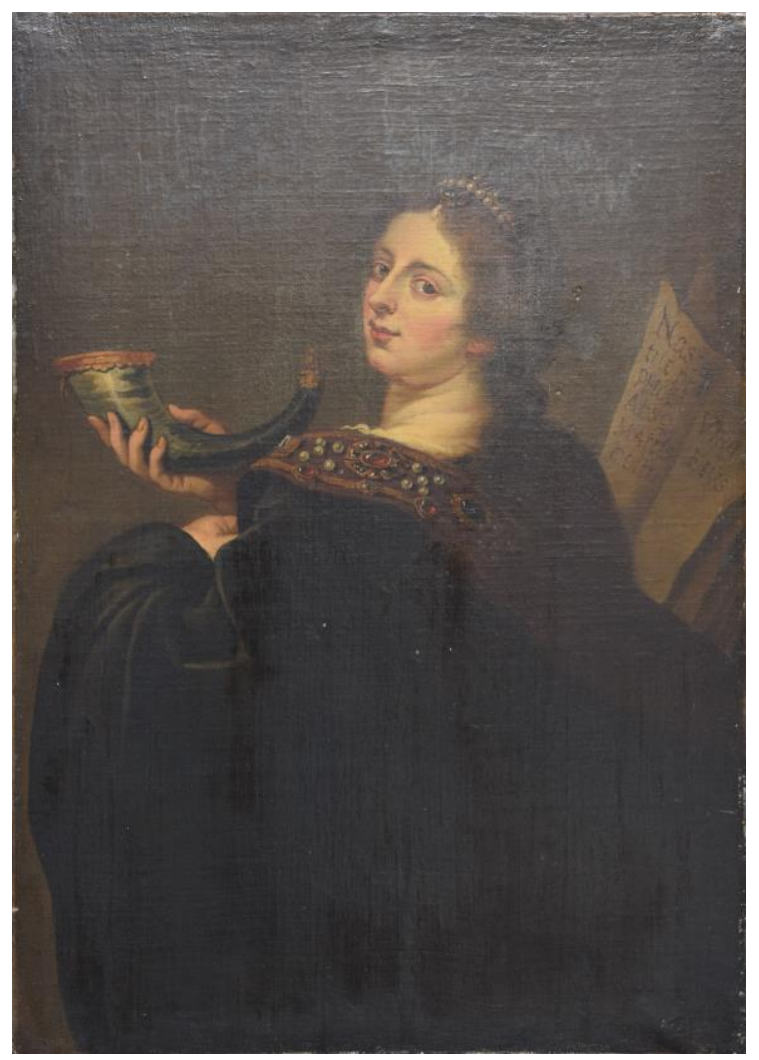

Fig. 5. Jan van den Hoecke. Sibila Délfica. Córdoba, colección privada. Foto del propietario@

Dios, Salvador], poema que se atribuye a la Sibila Eritrea, y razón por la que este animal se convirtió en el símbolo secreto de los primeros cristianos perseguidos. En la Ciudad de Dios, San Agustín, explica esta asociación e indica que la Eritrea es la sibila que proporciona la profecía más clara sobre Jesucristo. Pero ni Pedro de Cavalleria ni Barbieri proporcionan detalles sobre su apariencia. Al comparar el ejemplar madrileño con el de Le Mans, constatamos la alteración de este último por todos sus lados. Difiere ligeramente lo escrito en el libro en uno y otro ejemplar, permitiendo la comparación entre ambos completar los diferentes fragmentos del texto, que alude a los doce apóstoles y su humilde oficio de pescadores: eliget sibi de piscatoribus et abiectis numerum duodenarium [Los escogerá para sí de entre pescadores y humildes en número de doce]. Procedente de San Agustín, el texto es retomado por el humanista Marquardus de Susannis en su Tractatus de Juadeis publicado en $1658^{48}$. Una copia de otra mano y de pobre calidad conocemos por fotografía del archivo de las obras incautadas en la Guerra Civil española, perteneciente a la colección de Ramón Jordán

48 Marquardus de Susannis, Tractatus de Iudaeis et aliis infidelibus circa concernentia originem..., (Venecia, 1558), p. 107; Kenneth R. Stow, "The Papacy and the Jews: Catholic Reformation and Beyond", Jewish History, 6, no 1-2, (1992), pp. 257-279. 


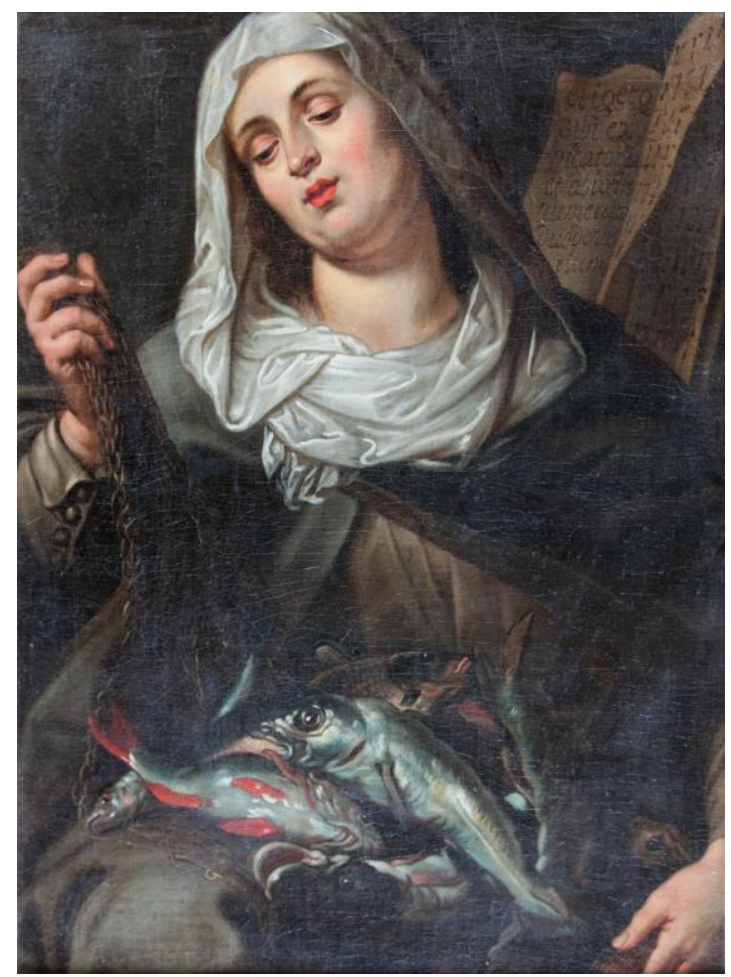

Fig. 6a. Jan van den Hoecke y taller. Sibila Eritrea. Le Mans, Musée de Tessé(C)

de Uría, vizconde de Roda, depositada provisionalmente en el museo del Prado en 1937 junto con una Sibila Helespóntica ${ }^{49}$.

La Sibila Cumana lleva un libro abierto con un dibujo de la resurrección de Cristo y el texto: Casta / fave Lucina tuus jam regnat Apollo [Protégelo, casta Lucina: ya reina tu Apolo], fragmento procedente de las Bucólicas o Églogas de Virgilio asociado a esta sibila y retomado por Barbieri ${ }^{50}$. Así lo leemos en los ejemplares de la antigua colección Campbell Smith ${ }^{51}$, de venta de Ámsterdam52, y del Museo de Le Mans ${ }^{53}$ (Fig. 7a). El pintor omite, no obstante, los signos de puntuación presentes en la fuente literaria. Consta-

\footnotetext{
49 Medidas desconocidas. Fotografía de Vicente Salgado Llorente, 1939. Fototeca del Instituto de Patrimonio Cultural Español (en adelante FIPCE), Archivo Arbaiza, (inv. no ARB-MP-01206.) (En red: http://www.mcu.es/fototeca patrimonio/show ficha.do?indice=1, consultada: 8 de febrero de 2019).

50 Virgilio, Bucólicas 4, 4-10. "Sybilla Cumana fuit tempore Tarquinii Prisci, scripsit de Christo haec, referente Virgilio in lib. Bucolic. In hunc modum: Ultima Cumaei venit jam carminis aetas; / Magnus ab integro saeclorum nascitur ordo. / Jam redit et virgo, redeunt Saturnia regna, / Jam nova progenies coelo demittitur alto. Casta, fave, Lucina, tuus jam regnat Apollo". Barbieri, en Mâle, L'Art réligieux, p. 259.

51 (Lienzo, $107 \times 76 \mathrm{~cm}$ ). Foto RKD no 25660, como Abraham Janssens.

52 (Lienzo, 107,4 x 76,6 cm). Ámsterdam, Christie's, (06-05-2008, lot. no 14, círculo de Jan van den Hoecke); Sanzsalazar, "Jan van den Hoecke...", p. 71, fig. 17.

53 Sin identificar, descrita como "Sibila con dos libros", (Lienzo, 87 x 62,4 cm). Le Mans, Musée de Tessé, (inv. no 10.643).
} 


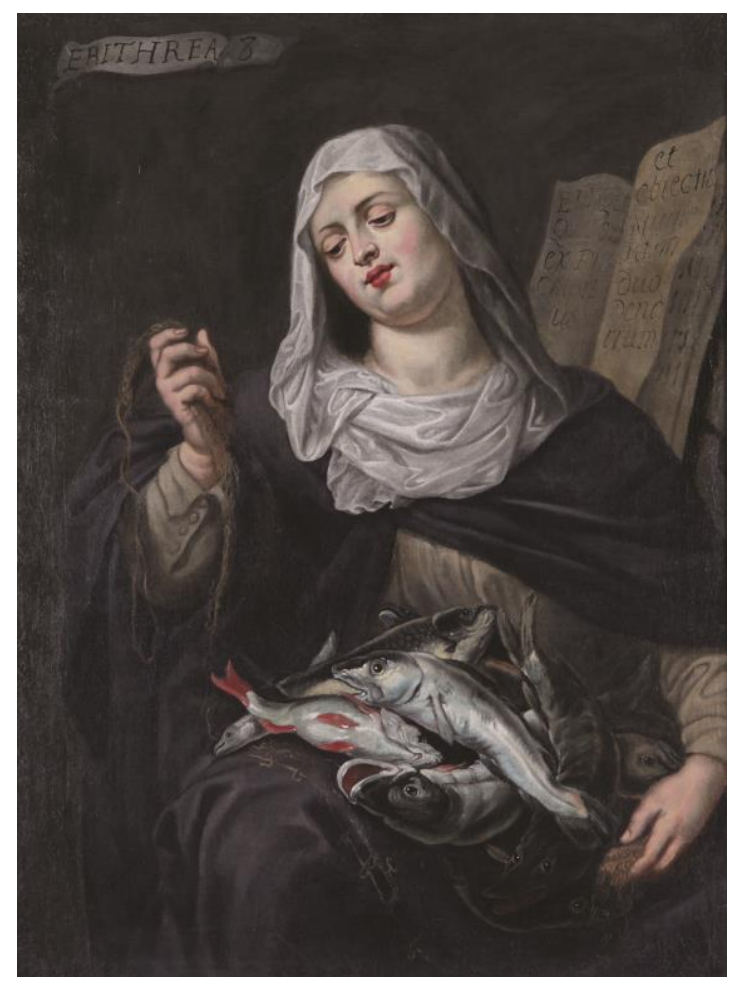

Fig. 6. Jan van den Hoecke. Sibila Eritrea. Madrid, colección particular. Foto del propietario@

tamos de nuevo en el ejemplar de Le Mans la presencia de repintes de pudor que cubren el escote y los brazos. Contiene el mismo texto que el ejemplar que conservaba la Bob Jones University hasta $1992^{54}$ (Fig. 7), pero la figura es más afín a otro ejemplar que lleva una banderola arriba con la inscripción "CVMANA" y un extracto de las Discordantiae de Barbieri asociado a la Sibila Frigia55: ex olympo excelso veniet et Firmabit Consilium in coelo [Desde el Olimpo excelso vendrá y en el cielo hará firme su designio] ${ }^{56}$.

De la Sibila Cimeria hemos localizado nueve ejemplares. Su representación coincide en imagen y profecía con el texto de Barbieri, que la describe vestida de azul y joven, con el cabello cayendo sobre la espalda57. En el

\footnotetext{
54 (Lienzo, $108 \times 76,8 \mathrm{~cm}$.) Procede, igual que la Sibila Délfica, del marchante Julius H. Weizner de Nueva York, ( $n^{\circ}$ 186, como Rubens); Greenville, Bob Jones University, (inv. n P.63.313.12), Jones, Supplement to the catalogue 1968, n 315, Abraham Janssens; Nueva York, Christie's, (16-01-1992, lot. no 55, círculo de Abraham Janssens). Rebeka Cobb, de la Bob Jones University, nos informa a través de comunicación escrita (2-01-2019) que este ejemplar figuró en Christie's (22-04-1992), dato que no hemos podido corroborar.

55 (Lienzo, $108 \times 81 \mathrm{~cm}$ ). Londres, Sotheby's (20-10-2009, lot. no 34, como seguidor de Abraham Janssens).

56 Fragmento de "Flagellabit Dominus potentes terrae, et Olympo excelso veniet et firmabit consilium in coelo et anuntiabitur virgo in valibus desertorum".

57 "Sibylla Emeria, in Italia nata, Chimica, vestita coelestina, veste deaurata, capillis per scapulas sparsis, et juvenis, de qua Ennius; ait: In prima facie virginis ascendet puella pulchra facie, prolixa capillis, sedens super sedem stratam dans ei ad comedendum vis proprium, id lac de coelo missum". Barbieri, en Mâle, L'Art réligieux, p. 259.
} 


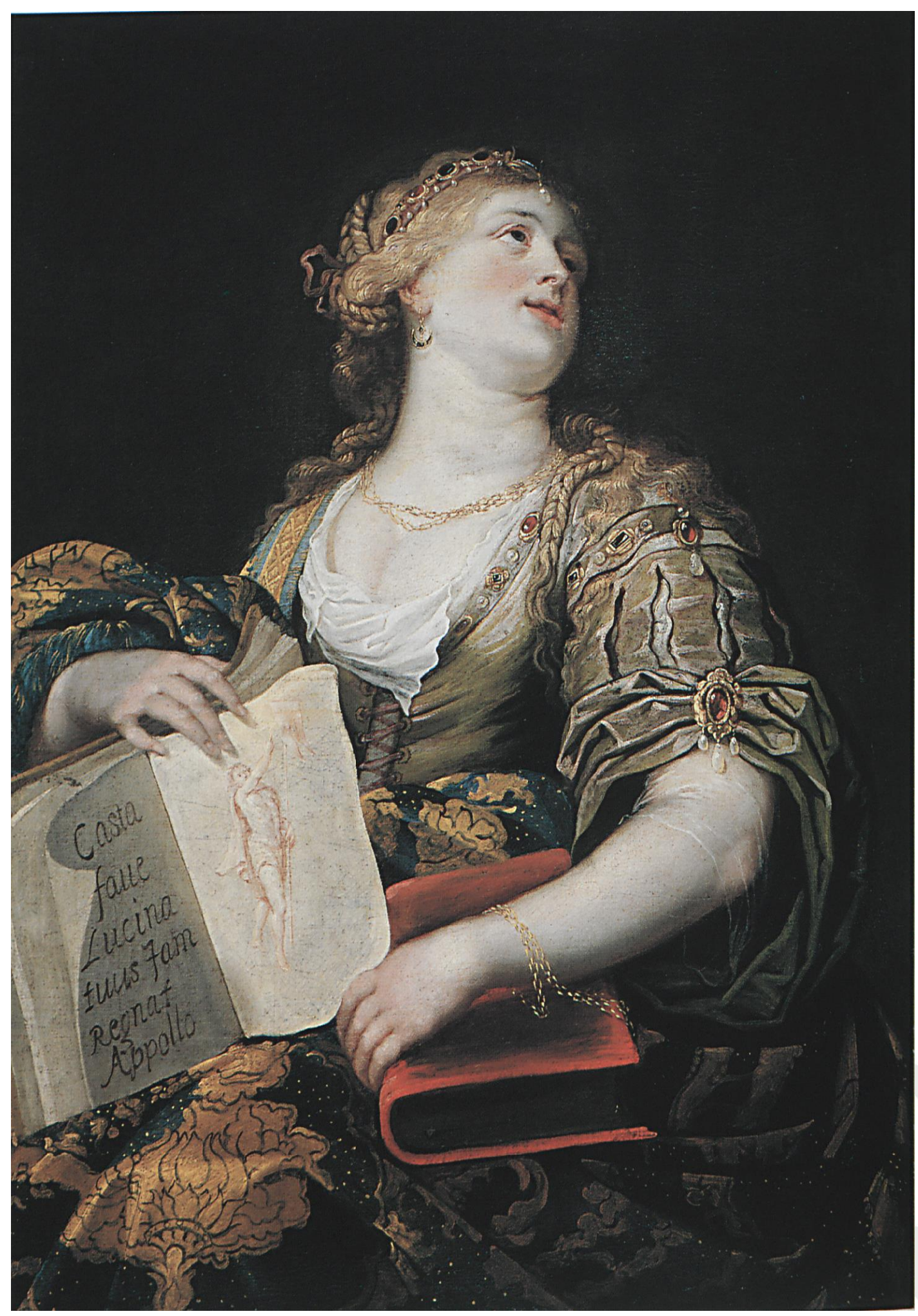

Fig.7. Jan van den Hoecke. Sibila Cumana. Paradero actual desconocido. 
ejemplar del museo de Le Mans ${ }^{58}$, al estar cortado, no se percibe la paloma del Espíritu Santo que vuela en el margen superior derecho (Fig. 8a). En la banderola se lee parcialmente el texto que el ejemplar procedente de la Bob Jones University nos permite leer ${ }^{59}$ (fig. 8): In prima facie virginis scendet puella pulchra facie [en el primer decanato de Virgo, surgirá una virgen de hermoso rostro $]^{60}$, inscripción que contiene también un ejemplar erróneamente atribuido a Abraham Janssens en venta española ${ }^{61}$. Tenemos referencia de otro, de calidad inferior, con la inscripción "SIB. CIMICA LLAW" en una filacteria en el margen superior izquierdo62. Por fotografía antigua conocemos otro, de mayor tamaño, que estuvo en posesión de A.L. Nicholson, en Londres, hacia $1927^{63}$, en cuya banderola se lee: "pulchr [...] cendet". El texto es imperceptible en la repetición que conserva el museo de Bruselas como anónimo ${ }^{64}$. El procedente de la colección Alcántara Villiers de Bruselas, restituido por Vlieghe a Jan Van den Hoecke, se vendió en fechas recientes como seguidor de Theodoor van Thulden ${ }^{65}$.

Existe otro ejemplar, con los ángulos redondos ${ }^{66}$, la inscripción "CIMMERIA" y la profecía: de radice virginis ascendet flos pulcher [De la raíz de una virgen surgirá una hermosa flor], texto que no consta en las Discordantiae de Barbieri sino en el libro de Isaías (11:1): Et egredietur virga de radice Iesse, et flos de radice eius ascendet, alusión a la genealogía de Jesús o al árbol de Jessé, de una de cuyas ramas nacerá el Mesías.

La Sibila Europea es, siguiendo a Barbieri, una mujer joven, elegante y de

\footnotetext{
58 Descrita como "Sibila escribiendo". (Lienzo, 82,5 x $66 \mathrm{~cm}$ ). Le Mans, Musée de Tessé, (inv. no 10.644).

59 (Lienzo, $108 \times 76,8 \mathrm{~cm}$ ). Greenville, Bob Jones University, (inv. no P.63.313.12), Jones, Supplement to the catalogue, 1968, n० 315, (atribuido a Abraham Janssens). Propiedad de Jack Hanger en noviembre de 1970; posteriormente en Nueva York, Christie's (10-01-1980, lot. no 107). $60 \mathrm{El}$ Dr. Guillermo Fatás, a quien hemos consultado para las traducciones del latín, apunta un error en el texto inscrito, pues debería ser "ascendit" en lugar de "ascendet"; y señala el original a partir del cual la frase inscrita ha degenerado: "In prima facie Virginis [en el primer rostro, o sea, fase; o decanato, es decir, en los primeros diez días del signo zodiacal Virgo] ascendit virgo quedam honesta et munda et est pulchra facie, prolixi capilla, sedens super sedem stratam, nutriens puerum...". Le reiteramos nuestro agradecimiento por sus observaciones y por su generosa ayuda.

61 (Lienzo, $108 \times 75 \mathrm{~cm}$ ). Madrid, Goya subastas (29-11-2010, lot. no 30), atribuido a Abraham Janssens; Madrid, Goya subastas, (06-07-2011, lot. no 74), atribuido a Abraham Janssens.

62 (Lienzo, 107,95 x 81,28 cm). Erróneamente identificada como "Sibila Cumana", en venta desconocida, (3-05-2015), como Abraham Janssens.

63 (Lienzo, $127 \times 101,6 \mathrm{~cm}$ ). Londres, A.L. Nicholson, 1927 (como Gaspar de Crayer).

64 (Lienzo, 111 x $80 \mathrm{~cm}$ ). Bruselas, Musées Royaux, (Inv. no 5042). Philippe Roberts-Jones y Henri Pauwels (dir.), Musées Royaux des Beaux-Arts de Belgique. Catalogue inventaire de la peinture ancienne, (Bruxelles: Musées Royausx des Beaux-Arts de Belgique, 1984), p. 423. Atribuido anteriormente a Theodoor van Thulden, hoy como anónimo y bajo el título de "Figura alegórica", (cliché kik-irpa: A102579); Vlieghe, "Nicht Jan Boeckhorst...", p. 166, nota 5, como Jan van den Hoecke.

65 (Lienzo, $106 \times 78 \mathrm{~cm}$ ), con la inscripción en la parte superior izquierda: "Cimmeria". Procedente de la colección de la marquesa Alcántara Villiers en Bruselas (1932); Paris, Pierre Berger \& Associés, (24-112010, lot. no 30), como seguidor de Theodoor van Thulden; Ámsterdam, Christie's, (1-11-2011, lot. no 124), como Jan van den Hoecke. Vlieghe, "Nicht Jan Boeckhorst...", p. 166, nota 5, fig. 3, (como Jan van den Hoecke); Galen, Johan Boeckhorst, p. 464.

66 (Lienzo, 104,4 x 77,5 cm). Londres, Sotheby's, (16-04-1997, lot. no 128), atribuido a Jan Boeckhorst.
} 


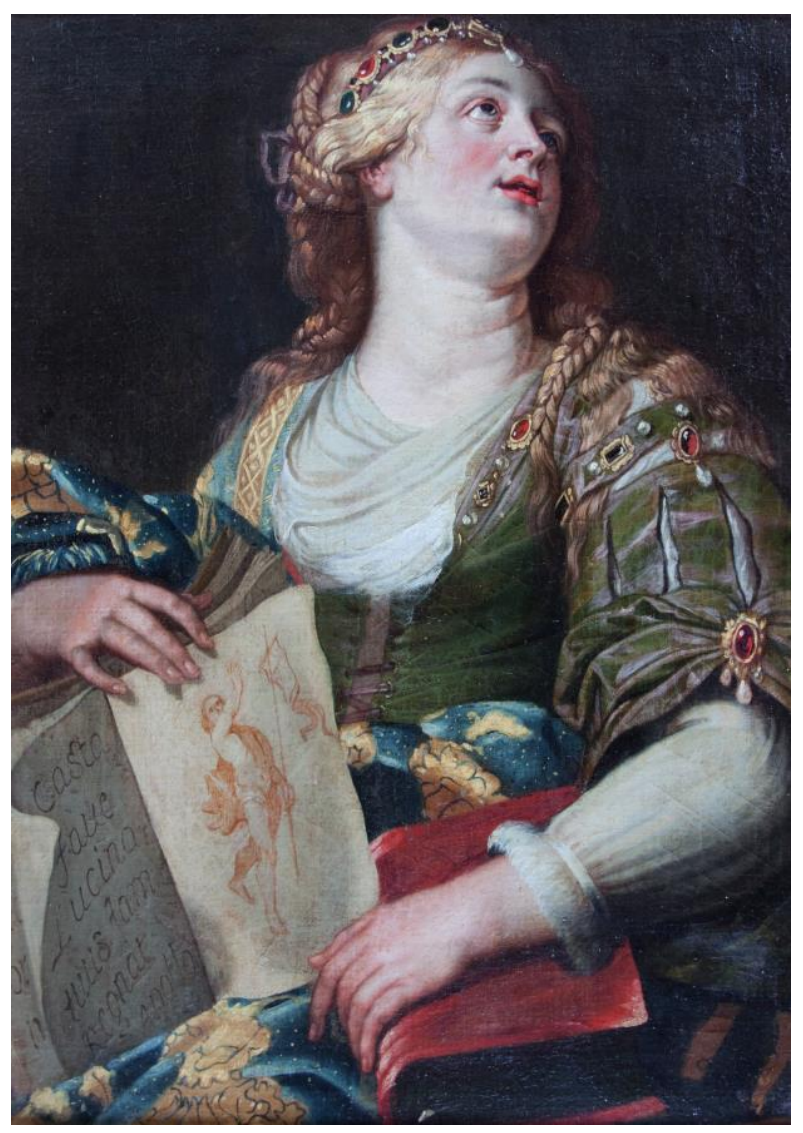

Fig. 7a. Jan van den Hoecke y taller. Sibila Cumana. Le Mans, Musée de Tessé@

rostro resplandeciente, vestida con manto dorado ${ }^{67}$. En lugar de la espada que lleva habitualmente en la mano esta sibila68, sostiene el cetro de Europa. El ejemplar del museo de Le Mans ${ }^{69}$ (Fig. 9a), deja ver parte del texto de su profecía que alude a Cristo: Regnabit in paupertate [reinará en la pobreza]. Con repintes de pudor en el escote y sin identificar su asunto, es claramente de calidad inferior al ejemplar de la antigua colección Campbell, localizado en sucesivas ventas con atribuciones a Veronés, Cornelis de Vos y Justus van Egmont ${ }^{70}$ (Fig. 9). Otra repetición, con los án-

\footnotetext{
67 "Sibylla Europa, decora, juvenis, facies rutilans, velo subtilissimo capita ligata, induta veste aurea, de Christo sic ait: Veniet ille et transibit montes et colles et latices sylvarum Olympi; regnabit in paupertate et dominabitur in silentio et egredietur de utero virginis". Barbieri, en Mâle, L'Art réligieux, p. 260.

68 La espada se menciona en el Livre d'Heures de Louis de Laval (fol. 23v) como alusión a la Masacre de los Inocentes.

69 Identificada según la inscripción "Ragnavit Pauperate", (Lienzo, 87 x 67,5cm). Le Mans, Musée de Tessé, (inv. no 10.645).

70 (Lienzo, 106,7 x 78,4 cm), con la inscripción "EVROPAEA" y "Regnabit in pauper". Berlín, colección H. Weustenberg; Berlín, Lepke, (27-10-1908, lot. no 64), como Paolo Veronese; Amberes/Nueva York, Galería Samuel Hartveld. Anunciado en el Burlington Magazine como Jan Boeckhorst, (Feb, 1937, p. iii); Bruselas, colección P. Visser; Historische schatten van Vlaanderen, cat. Exp. (Kampen, Overijssel), 1965), cat. 124, como Cornelis de Vos; Monaco, Christie's, (03-12-1988, lot. no 18), como Justus van Egmont; Londres, Christie's, (19-05-1989, lot. no 140), como Justus van Egmont; Londres, Christie's, (10-07-10, lot. no 143), como Justus van Egmont.
} 


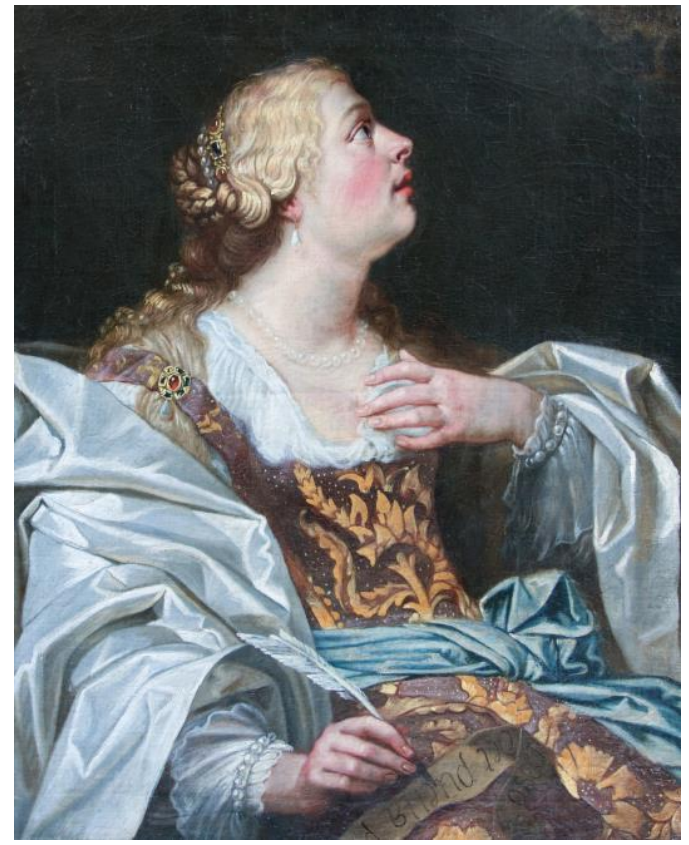

Fig. 8a. Jan van den Hoecke y taller. Sibila Cimeria. Le Mans, Musée de Tessé(C)

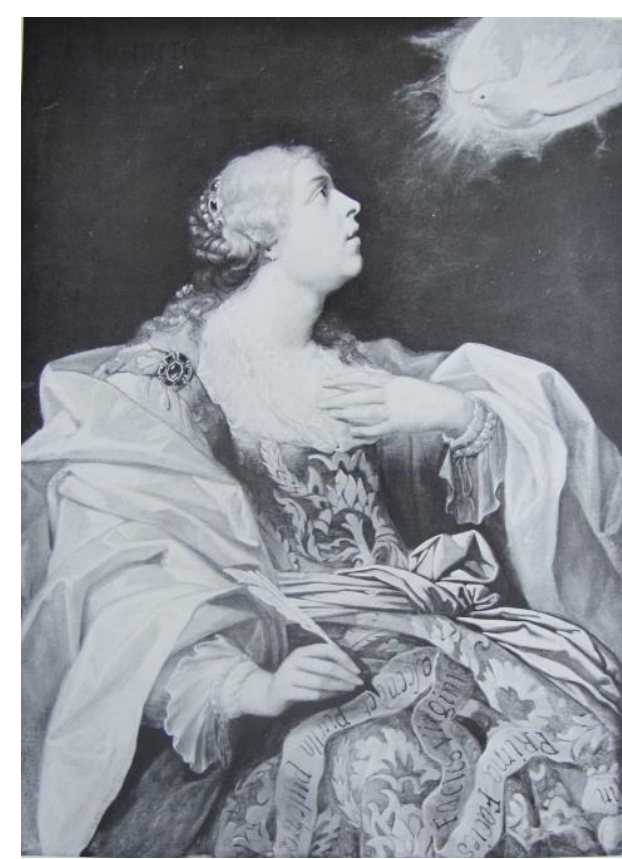

Fig. 8. Jan van den Hoecke. Sibila Cimeria. Paradero actual desconocido. Anteriormente en Greenville, Bob Jones University

gulos en redondo ${ }^{71}$, figuro en venta en 1997, como pareja de la Sibila Cimeria, y dos más conocemos por referencias de ventas ${ }^{72}$.

En cuanto a la Sibila Pérsica, el ejemplar del museo de Le Mans ${ }^{73}$ (Fig. 10a), está mutilado y con repintes de pudor igual que los demás de la serie, como puede comprobarse al compararlo con el de colección privada española, que restituimos años atrás a Jan Van den Hoecke y que se atribuía a Rubens ${ }^{74}$ (Fig. 10). Un tercero conocemos por una antigua fotografía, en posesión del marchante emigrado a Nueva York Samuel Hartvelt (Amberes, 1878-1949), que lo tuvo como obra de Rubens ${ }^{75}$. Quizá se trate del mismo que, guardado en una colección privada de Lombardía durante 30 años, ha sido expuesto en 2016 en el Palazzo Petrignani de Amelia, y presentado como un Rubens descubierto, con gran eco de la pren-

\footnotetext{
71 (Lienzo, 104,4 x 77,5 cm). Londres, Sotheby's, (16-04-1997, lot. no 129), atribuído a Jan Boeckhorst. 72 (1) (Lienzo, 104,1 x 71,1 cm). Procede de la colección S. Harveld de Amberes, (1937); Bruselas, R. van den Boreck (1960); Nueva York, Sotheby's, (24-04-1995, lot. no 117), como Jaspar y Jan van den Hoecke; Nueva York, Sotheby's, (17-01-1996, lot. no 19), como Jaspar y Jan van den Hoecke. (2) (Lienzo, $105 \times 78,5 \mathrm{~cm}$ ). Pau, Gestas, (24-11-1996, lot. no 14), como Johan Boeckhorst, vendida junto a una Sibila Cimeria sin reproducir.

73 (Lienzo, 89,5 x 66 cm.) Le Mans, Musée de Tessé, (inv. no 10.646).

74 (Lienzo, 106,5 x 76,4 cm). Madrid, colección privada. Sanzsalazar, "Jan van den Hoecke...", pp. 5355, fig. 4, nota 42. Probablemente se trate de la procedente de Colonia, J. P. Weyer, 1852. Cit. Galen, Johann Boeckhorst, p. 362, que ilustra este ejemplar con pie de foto erróneo.

75 (Lienzo, 107 x $78 \mathrm{~cm}$ ). Sanzsalazar, "Jan van den Hoecke...", p. 53, nota 42. Se cita en la monografía de Jan Boeckhorst pero no es la que ilustra, Galen, Johann Boeckhorst, p. 364, que corresponde en realidad al ejemplar en colección privada española.
} 


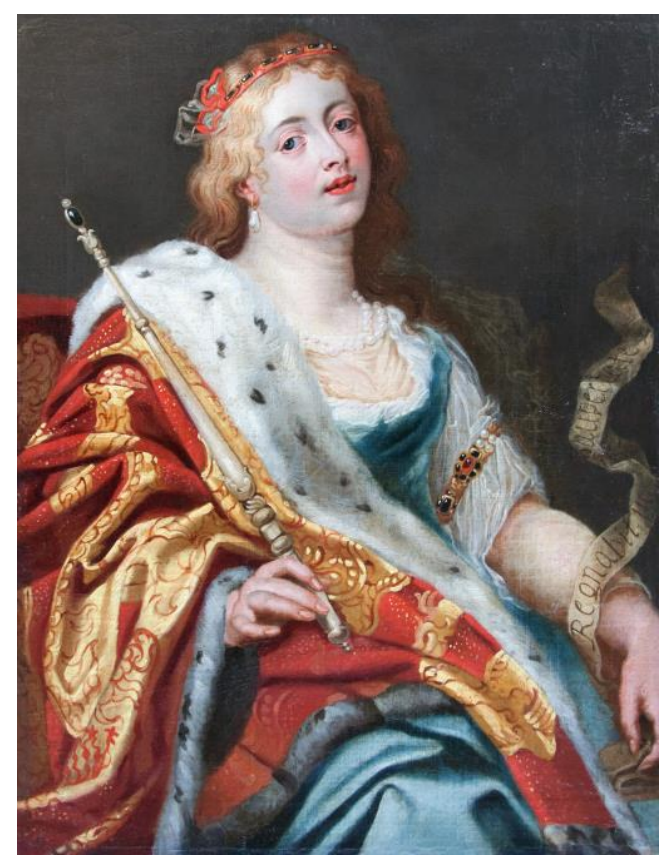

Fig. 9a. Jan van den Hoecke y taller. Sibila Europea. Le Mans, Musée de Tessé(C)

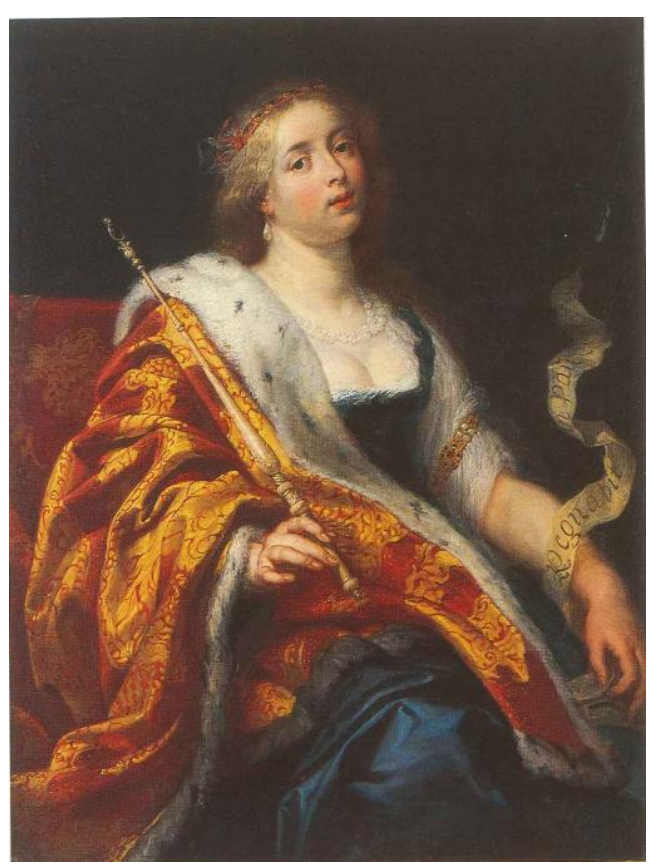

Fig. 9. Jan van den Hoecke. Sibila Europea. Paradero actual desconocido

sa italiana ${ }^{76}$. Este prototipo lleva un libro abierto en la mano con un fino dibujo de la Virgen y el Niño pisando la serpiente del pecado, donde se lee el texto de Barbieri correspondiente a su profecía: Ecce bestia concu/caberis et gignetur dom/ inus in orbe terrarum et gremium virginis erit salus Gentium, [Bestia, serás pisoteada y el señor será concebido en el mundo y en el seno de una virgen será la salvación]. En cambio, la representación no concuerda con Barbieri, que la describe vestida de oro y con velo blanco en la cabeza, sino con los grabados de Baccio Baldini (1470-1478) ${ }^{77}$, cuyo texto la describe sentada, con un libro en la mano, y haciendo un gesto con la mano derecha.

Habitualmente publicada como sibila sin nombre, la siguiente sibila, con la cabeza vuelta hacia arriba y la mirada al cielo, lleva también un libro abierto en la mano, y el brazo apoyado en la cesta del Niño Jesús (Fig. 11a). La inscripción del libro permite reconstruir el texto de su profecía: De excelsis caelorum habitaculo prospexit deus humiles suos. Et nascetur in diebus novissimis de virgine hebraea in cunabulis terrae [Desde su morada en la

\footnotetext{
76 Siguiendo el peritaje de Giovanni Testori (2-09-1986), que lo atribuye sin dudar a Rubens. Vittorio Sgarbi (coord..), Rubens. Allegoria della Fede. La Sibilla Persica. Opera inedita, (Amelia: Museo Civico Archeologico e Pinacoteca Edilberto Rosa, 13-10-2016/8-01_2017). También en: "Rubens e la Sibilla dal mento 'pensante' ", Corriere della Sera, (16-09-2016). Ad Amelia un'opera inedita di Rubens. (En red: https://www.sistemamuseo.it/ita/5/news/3286/amelia-umbria-ad-amelia-unopera-inedita-dirubens/\#.XFykxdFCfJx (consultada: 8 de febrero de 2019).

77 A propósito de las Sibilas de Baccio Baldini: Arthur Mayger Hind, Early Italian Engraving, a critical catalogue, (London, 1938), CII, 1-12; Robin Raybould, The Sibyl Series of the Fifteenth Century, (Leiden-Boston, 2016), pp. 130-136.
} 


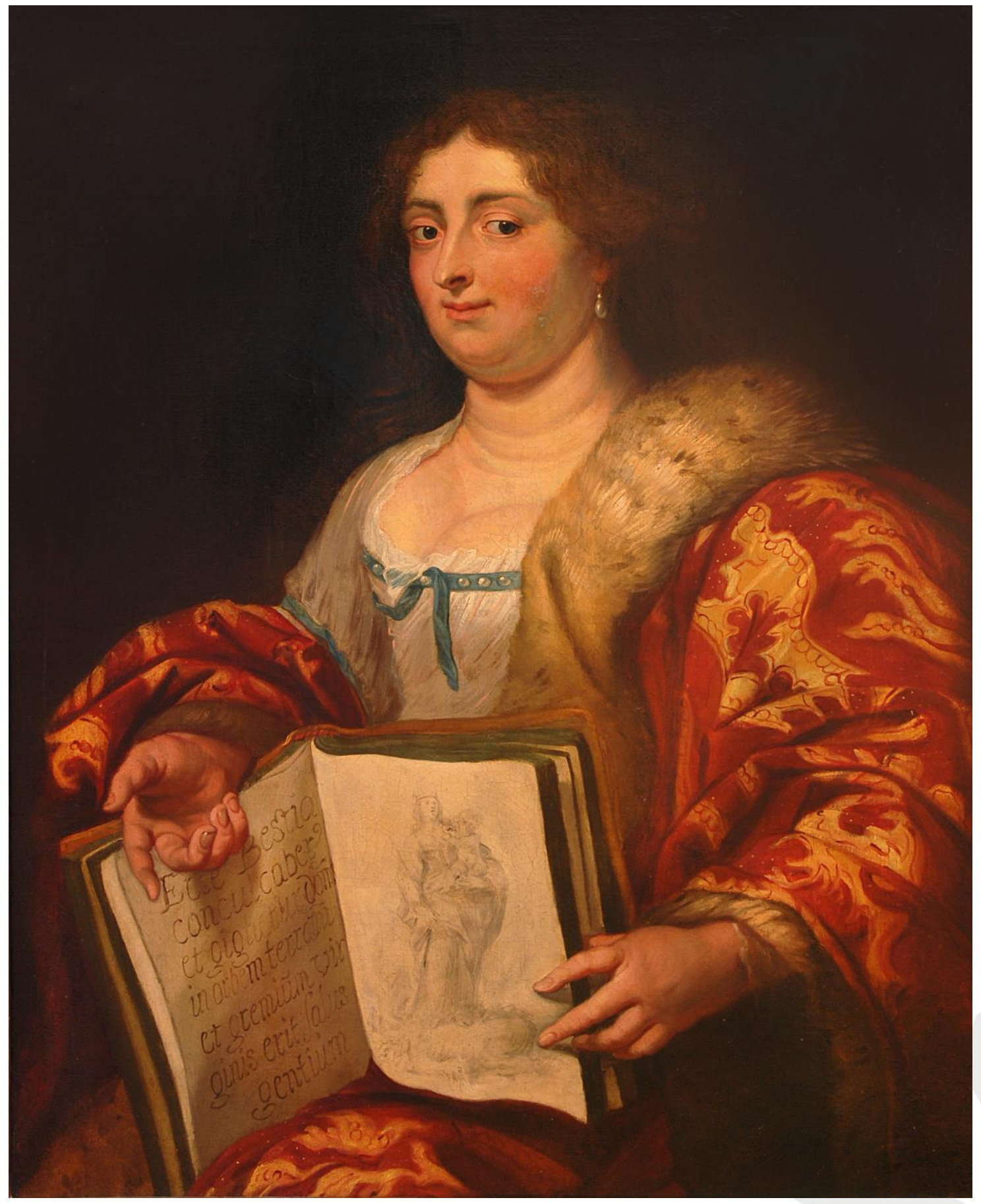

Fig. 10. Jan van den Hoecke. Sibila Pérsica. Madrid, colección particular. Foto del propietario@ 


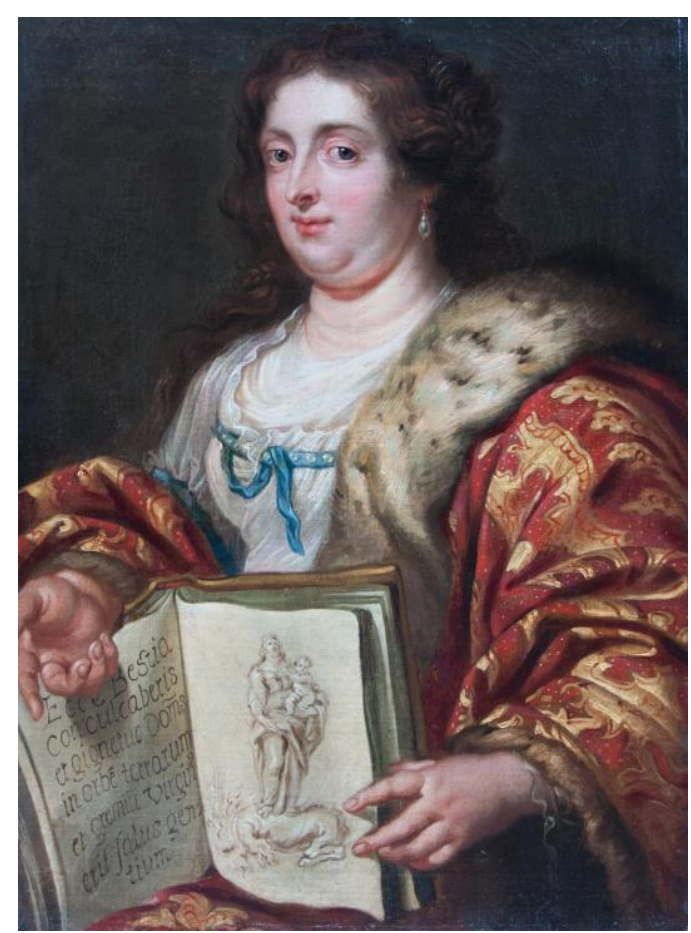

Fig. 10a. Jan van den Hoecke y taller. Sibila Pérsica. Le Mans, Musée de Tessé(C)

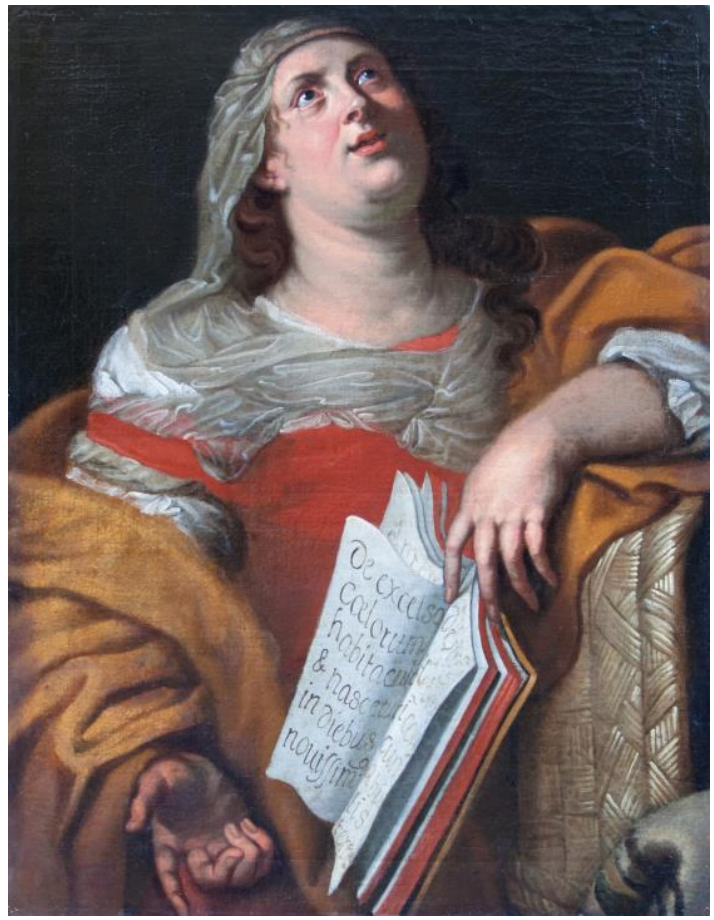

Fig. 11a. Jan van den Hoecke y taller. Sibila Helespóntica. Le Mans, Musée de Tessé@

excelsitud de los cielos Dios miró a su abatido pueblo [lit.: a sus humildes]. Y en los últimos días nacerá [Dios] de una virgen hebrea en la cuna de la tierra ${ }^{78}$. Se sigue aquí el texto de Barbieri, retomado por Marquardus de Susannis $^{79}$, que lo atribuye a la Sibila Helespóntica. Coincide su representación como anciana, con un velo en la cabeza cubriéndole el pecho y cayendo sobre los hombros. Otro ejemplar conocido, publicado también como "Sibila sin nombre", pertenece a la serie de Campbell, Escocia $(1951)^{80}$; y un tercero fue venido en Londres con atribución a Gaspar van den Hoecke ${ }^{81}$ (Fig. 11). La inscripción "HELESPOTICA" figura en el margen superior izquierdo de una copia de pobre calidad que conocemos por fotografía de los bienes incautados durante la Guerra Civil española, perteneciente a la colección del vizconde de Roda, junto a una Sibila Eritrea, como apuntamos líneas atrás ${ }^{82}$.

\footnotetext{
78 Descrita por la inscripción como" Sibila de Excelsio", (Lienzo, 85 x $66 \mathrm{~cm}$ ). Le Mans, Musée de Tessé, (inv. no 10.647).

79 Fra Marquardus de Susannis, Tractatus de Iudaeis, 1568, fols. $138 \mathrm{v}-139 \mathrm{r}$.

80 Vlieghe, "Nicht Jan Boeckhorst...", p. 170, fig. 10; Galen, Johan Boeckhorst, p. 364.

81 (Lienzo, 103,5 x 76,2 cm). Londres, Christie's, (12-12-2003, lot. no 8), como Gaspar van den Hoecke; Londres, Christie's, (23-04-2004, lot. no 25), como Gaspar van den Hoecke.

82 Medidas desconocidas. Fotografía de Vicente Salgado Llorente, 1939. FIPCE, Archivo Arbaiza, inv. ARB-MP-01206. (en red: http://www.mcu.es/fototeca patrimonio/show ficha.do?indice=1, consultada el 8 de febrero de 2019).
} 


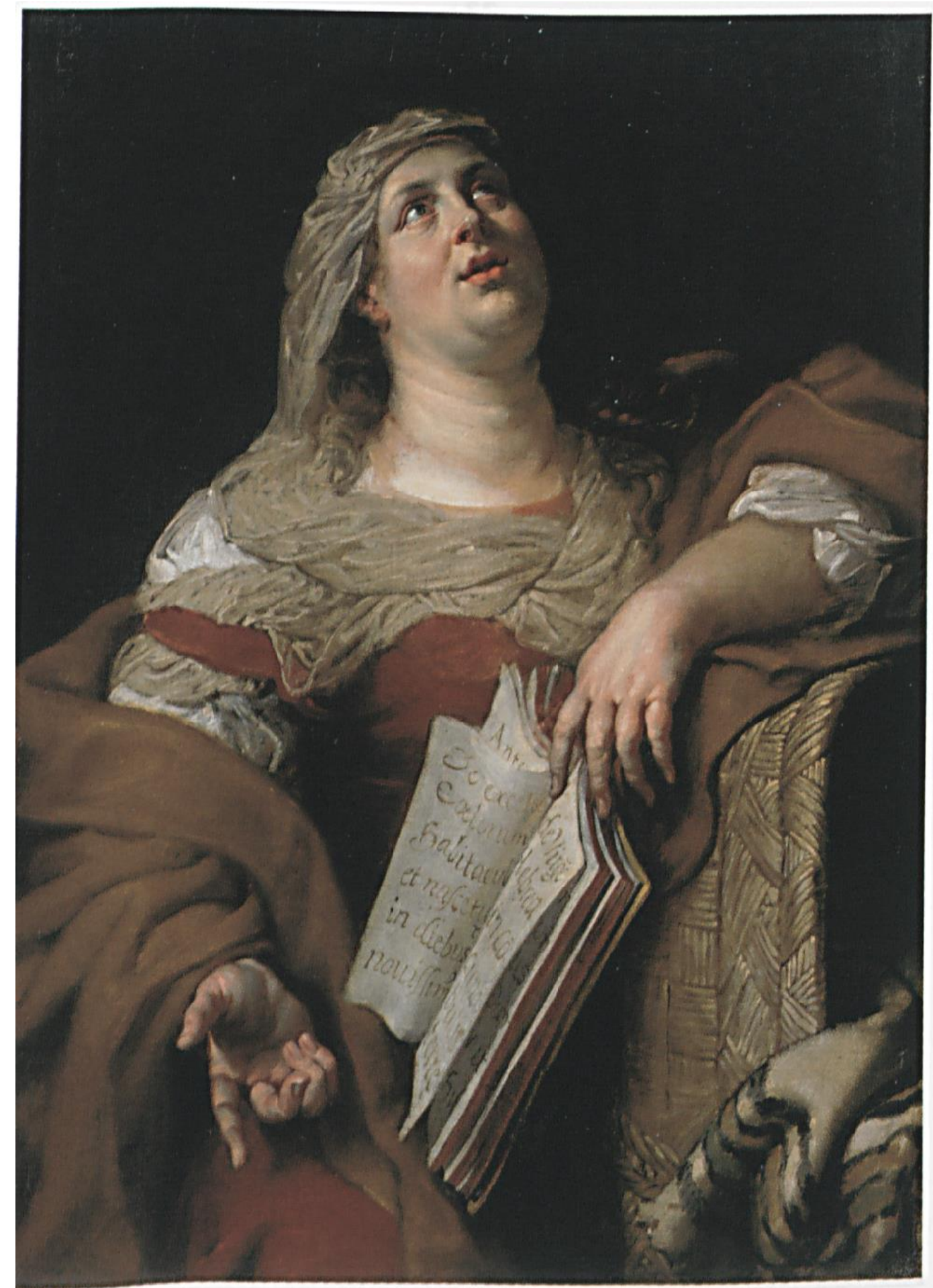

Fig. 11. Jan van den Hoecke. Sibila Helespóntica. Paradero actual desconocido 


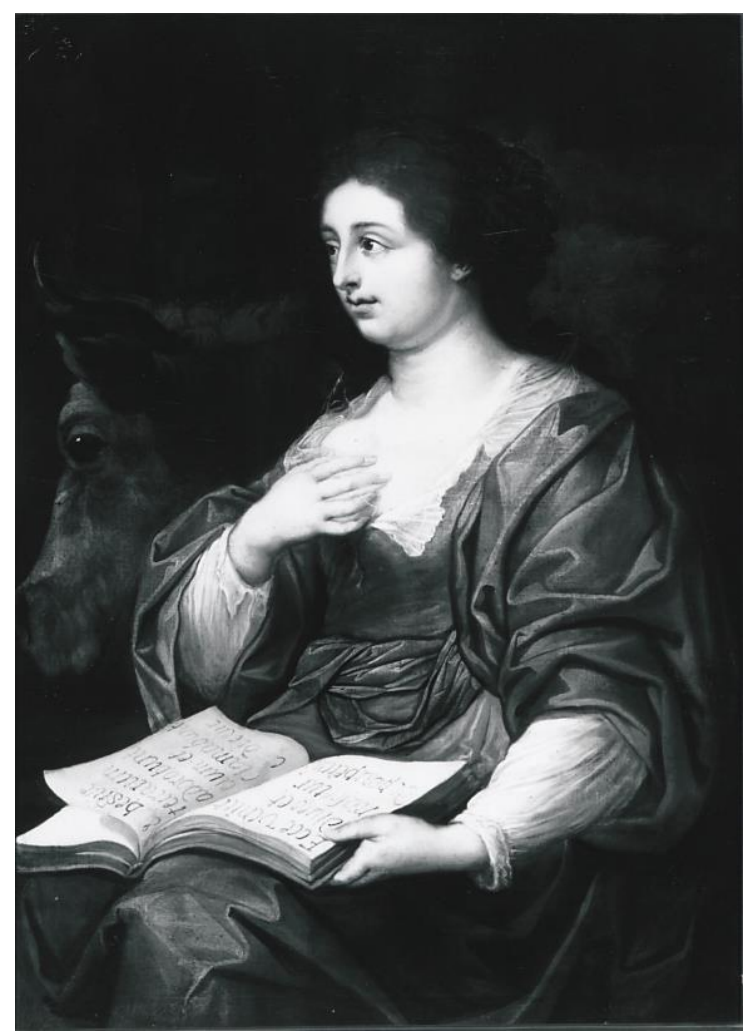

Fig. 12. Jan van den Hoecke. Sibila de Samos. Paradero actual desconocido.

Por último, la Sibila de Samos lleva un libro donde se leen fragmentos de su profecía según las Discordantiae Barbieri: Ecce veniet dies et nascetur de paupercula et bestiae terrarum adorabunt eum et dicent «laudate eum in atriis colorum» [He aquí que un día vendrá y nacerá de menesterosos, y las bestias de la tierra lo adorarán, y dirán: alabadlo en las moradas

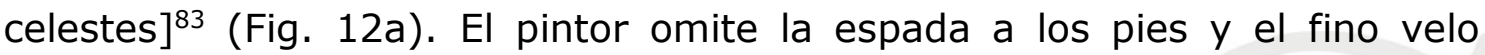
sobre la cabeza con que la describe Barbieri, y representa junto a ella un buey y una mula, como ilustración de "las bestias de la tierra" y por asociación a la Natividad, representación de la que se encuentran precedentes en manuscritos miniados. De este ejemplar localizamos otras dos repeticiones, una de estimable calidad atribuida a Kaspar van den Hoecke $^{84}$ (Fig. 12), y otra más pobre tenida como anónima85.

En conclusión, la calidad variable de las diversas repeticiones de estas series de Sibilas de Jan van den Hoecke y su elevado número son prueba de

83 Sin identificar, bajo el título de Sibila Ecce vienet, (Lienzo, $89 \times 68 \mathrm{~cm}$ ). Le Mans, Musée de Tessé, (inv. no 10.648).

84 (Lienzo, 106,7 x 76,8 cm). Por tradición se dice procede de la familia Bonaparte, adquirida en 1857, según informa Sotheby's, Nueva York, (19-04-1996, lot. no 100), como obra de Gaspar van der Hoecke. Se trata sin duda de un lapsus, queriendo decir Jan van den Hoecke, pues se cita en el artículo de Hans Vlieghe.

85 (Lienzo, $100 \times 79 \mathrm{~cm}$ ), con la inscripción, arriba a la derecha: «SAMIA». Florencia, Pandolfini, (09.05.2006, lot. no 263), como anónimo flamenco. 


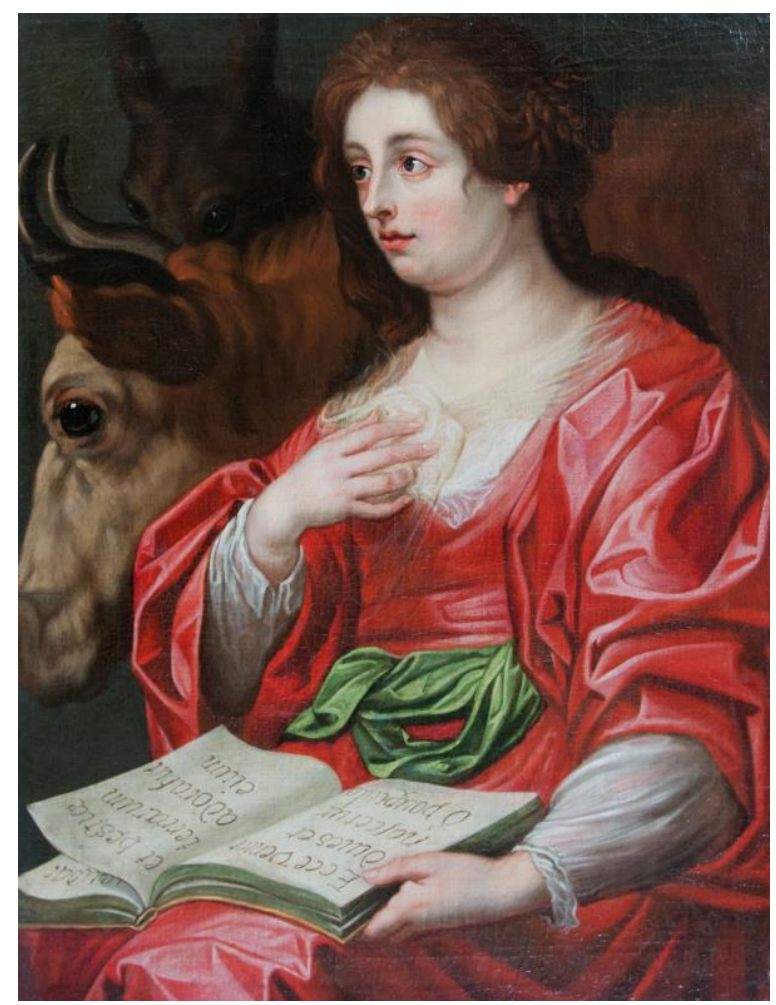

Fig. 12a. Jan van den Hoecke y taller. Sibila de Samos. Le Mans, Musée de Tessé(

una fuerte demanda que el pintor satisface con esfuerzo cambiante. Visiblemente fue el creador de una iconografía propia, extremadamente original. Se aleja de precedentes formales muy recurridos como los publicados por Crispijn van der Passe $^{86}$ y acude para las profecías fundamentalmente a las Discordantiae de Filippo Barbieri, permitiéndose ciertas licencias y sin limitarse a una sola fuente, pues se alimenta también de otras, como los textos grabados por Baccio Baldini, la Ciudad de Dios de San Agustín, el libro de Isaías o el evangelio según San Juan.

86 Crispijn van der Passe, XII Sibyllarum icones elegantissimi, (s.I., 1601); Hollstein 1974, p. 167 y ss.; J. Schlueter, "De Passe and the Sibyls ", Print Quarterly, 27, (2010), pp. 62-64. A. Rodríguez Romero y A. Ojeda, "Sibilas en Europa y América. repercusiones del Sibyllarum Icones de Crispijn de Passe en los siglos XVII y XVIII", Archivo Español de Arte, 88, 351, (2015), pp. 263-280. 
Bibliografía:

Ámsterdam 2008: Black is beautiful: Rubens tot Dumas, eds. Elmer Kolfin y Esther Schreuder, (Zwolle: Waanders Publishers, 2008).

Barbieri 1481: Filippo Barbieri, Discordantiae nonnullae inter sanctum Hieronymum et Augustinum, (Roma, 1481).

Bruselas 2007-2008: Rubens, L'Atelier du génie, ed. Joos van der Auwera, (Bruxelles: Musées Royaux des Beaux Arts de Belgique, 2007-2008).

Cavallería 1592: Pedro de la Cavallería, Tractatus Zelus Christi contra Iudaeos, Sarracenos, \& infideles. Ab illust..., (Venetiis: apud Baretium de Baretijs, 1592).

Duverger 1984-2009: Erik Duverger, Antwerpse kunstinventarissen uit de zeventiende eeuw, (Brussel: Koninklijke Vlaamse Academie van België voor Wetenschappen en Kunsten, 1984-2009), 14 vols.

Galen 2012: Maria Galen, Johan Boeckhorst. Gemälde und Zeichnungen, (Hamburg, 2012).

Heinz 1967: Gunter Heinz, "Studien über Jan van den Hoecke und die Malerei der Niederländer in Wien", Jahrbuch der Kunsthistorische Sammlungen in Wien, 63, (1967), pp. 109-164.

Hélin 1936: Maurice Hélin, "Un texte inédit sur l'iconographie des sibylles", Revue belge de Philologie et d'Histoire, tome 15, fasc. 2, (1936), pp. 349366.

Hind 1938: Arthur Mayger Hind, Early Italian Engraving, a critical catalogue, (London, 1938).

Hollstein 1974: Friedrich Wilhelm Hollstein, Hollstein's Dutch and Flemish etchings, engravings and woodcuts, ca.1450-1700, Vol. XV, (Amsterdam, 1974).

Jones 1968: Beneth A. Jones, Bob Jones University Supplement to the catalogue the art collection, paintings acquired 1963-1968, (Greenville, SCarolina: Bob Jones University, 1968).

Kampen 1965: Historische schatten van Vlaanderen, (Kampen: Overijssel, 1965).

Lahrkamp y Langemeyer 1982: Helmut Lahrkamp y Gerhard Langemeyer, "Der 'Lange Jan'. Leben und Werk des Malers Johann Boeckhorst 16041668", Westfalen, 60, (1982), n० 1, pp. 1-199.

Laval: Louis de Laval, Livre d'Heures, Libro de Horas de Luis de Laval, edición facsímil del Ms 920 de la Bibliothèque Nationale de France, (Burgos, 2013). 
Libourne 2006: Marguerite Stahl y Jean-Marie Darmian, Éloge du collectionneur Antoine-Victor Bertal (Créon, 1817-Nice, 1895), Libourne (Chapelle du Carmel, Mai/Octobre 2006), (Bordeaux: Le festin, 2006).

Mâle 1925: Émile Mâle, L'Art réligieux de la fin du Moyen Age en France, (Paris, 1925).

Martin 1972: J.R. Martin, The decorations for the Pompa introtius Ferdinandi, Corpus Rubenianum Ludwig Burchard (London-New York: Oxford University Press, 1972).

Martin 2005: G. Martin, Rubens. The Ceiling Decoration of the Banqueting Hall, Corpus Rubenianum Ludwig Burchard, XV, (London/Turnhout: Harvey Miller/ Brepols, 2005), 2 vols.

McGrath 2005: Elizabeth McGrath, "Sibyls, Sheba and Jan Boeckhort's 'Parts of the World'", en Florissant. Bijdragen tot de kunstgeschiedenis der Nederlanden (15de-17de eeuw). Liber amircoum Carl Van de Velde, (Brussel: VUB Press, 2005), pp. 357-370.

Passe 1601: Crispijn van der Passe, XII Sibyllarum icones elegantissimi, (s.l., 1601).

Raybould 2016: Robin Raybould, The Sibyl Series of the Fifteenth Century, (Leiden-Boston, 2016).

Robert-Jones y Pawels 1984: Philippe Roberts-Jones y Henri Pawels (dir.), Musées Royaux des Beaux-Arts de Belgique. Catalogue inventaire de la peinture ancienne, (Bruxelles: Musées Royaux des Beaux-Arts de Belgique, 1984).

Rodríguez Romero y Ojeda 2015: Agustina Rodríguez Romero y Almerindo Ojeda, "Sibilas en Europa y América. repercusiones del Sibyllarum Icones de Crispijn de Passe en los siglos XVII y XVIII", Archivo Español de Arte, 88, n० 351, (2015), pp. 263-280.

Sanzsalazar 2013: Jahel Sanzsalazar, "Jan van de Hoecke: quelques précisions et nouvelles propositions pour le catalogue de son oeuvre", Revue Belge d'archéologie et d'histoire de l'art/ Belgisch tijdschrift voor oudheidkunde en kunstgeschiedenis, 82, (2013), pp. 45-78.

Schlueter 2010: J. Schlueter, "De Passe and the Sibyls ", Print Quarterly, 27, (2010), pp. 62-64.

Stow 1992: Kenneth R. Stow, "The Papacy and the Jews: Catholic Reformation and Beyond", Jewish History, 6, no. 1-2, (1992), pp. 257-279.

Susannis 1558: Fra Marquardus de Susannis, Tractatus de Iudaeis et aliis infidelibus circa concernentia originem..., (Venetiis, 1558).

Tátrai 2007: Julia Tátrai, "Jan van den Hoecke. Hercules at the Crossroads", Arte Venustas. Studies on drawings in honour of Térez Gerszi, (Budapest, 2007), pp. 152-154. 
Virgilio 1829: Las Bucólicas de Publio Virgilio Maron, traducidas en versos castellanos, con notas y observaciones criticas por Don Felix M. Hidalgo, (Sevilla: H. Davila Llera y Co., 1829).

Vlieghe 2009: Hans Vlieghe, "Nicht Jan Boeckhorst, sonder Jan van den Hoecke", Westfalen, 68, (1990), pp. 166-218.

Enviado:08/02/2019

Aceptado:17/05/2019 